\title{
Investigación, gestión
}

y procesos formativos

\section{en educación}

Julieta López Zamora, Dennise Islas Cervantes

y Ernesto Israel Santillán Anguiano

(Coordinadores)

Qartuppi 


\section{(c) $(0)$}

Esta obra se edita bajo una licencia Creative Commons

Atribución-NoComercial-CompartirIgual 4.0 Internacional. 


\section{Investigación, gestión y procesos formativos en educación}

Julieta López Zamora, Dennise Islas Cervantes

y Ernesto Israel Santillán Anguiano

(Coordinadores) 
Obra dictaminada por:

María Virginia Bon Pereira

Universidad de Monterrey

Ma. Antonia Miramontes Arteaga

Universidad Autónoma de Baja California

Investigación, gestión

y procesos formativos en educación

1era. edición, septiembre 2021

ISBN 978-607-8694-14-3

DOI 10.29410/QTP.21.12

D.R. (C) 2021. Qartuppi, S. de R.L. de C.V.

Villa Turca 17, Villas del Mediterráneo

Hermosillo, Son. 83220 México

http://www.qartuppi.com

Edición y Diseño: Qartuppi, S. de R.L. de C.V.

Fotografía de portada: Adrian Varzaru, Scopio 


\section{Tabla de contenido}

7 Introducción

Julieta López Zamora, Dennise Islas Cervantes

y Ernesto Israel Santillán Anguiano

10 Capítulo 1

Interdisciplina, innovación y aprendizaje significativo.

Posibles aplicaciones en educación superior

Miguel Ángel Domínguez Cruz, Ernesto Israel Santillán Anguiano

y Reyna Isabel Roa Rivera

24 Capítulo 2

Dificultades de aprendizaje e inclusión:

un análisis desde la neuroeducación

Elena Hatty Jiménez Pérez, Dennise Islas Cervantes

y Leidy Hernández Mesa

51 Capítulo 3

Estrategias didácticas para docentes en la enseñanza del derecho Ariana Alejandra Atilano Bravo y Julieta López Zamora 
71 Capítulo 4

Desarrollo de estrategias didácticas para promover el aprendizaje significativo en preparatoria abierta

Ana Teresa Quintero Pacheco y Francisco Javier Arriaga Reynaga

89 Capítulo 5

Enseñanza de la danza folclórica en un entorno multidisciplinar y virtual

Gloria Patricia Olguín Reyes, Aidee Espinosa Pulido

y Maria Amparo Oliveros Ruiz

104 Capítulo 6

Aprendizaje cooperativo con el apoyo del teléfono inteligente durante clases a distancia por COVID-19

Gabriela Álvarez Plancarte, Clotilde Lomeli Agruel

y Claudia Araceli Figueroa Rochín 


\section{Introducción}

Este libro es la suma de esfuerzos de estudiantes y miembros del núcleo académico de la Maestría en Educación de la Universidad Autónoma de Baja California (UABC). En él convergen distintas miradas sobre la investigación e intervención educativa, pero con un mismo objetivo: la transformación a través de experiencias formativas que permitan diseñar, implementar y evaluar proyectos de innovación que favorezcan las formas de apropiación y uso de los conocimientos teóricos, técnicos y metodológicos, para solucionar problemas concretos en el ejercicio de la práctica docente y de la gestión educativa, de acuerdo con la realidad de sus contextos profesionales.

Los seis capítulos que integran esta obra se desarrollaron con base en los proyectos de intervención educativa socialmente pertinentes, en la iniciativa pública y privada del sector educativo y organizacional de educación básica, media superior (bachilleratos técnicos y generales) y superior, en apego a las líneas de generación y aplicación del conocimiento en procesos formativos y gestión educativa.

A lo largo del libro podemos encontrar capítulos como el de Domínguez, Santillán y Roa, quienes presentan diferentes estudios que dialo- 
gan sobre la importancia de aplicar enfoques interdisciplinarios como parte esencial del proceso de enseñanza-aprendizaje y la forma en la cual pueden ser útiles y pedagógicos en la educación, donde suele ser una tarea compleja de realizar, pero necesaria para abordar soluciones innovadoras a problemáticas difíciles de visualizar.

El capítulo presentado por Jiménez, Cervantes y Hernández es un trabajo de revisión teórica que aborda a los aportes neurocientíficos como una nueva mirada que brinda conocimientos clave para la enseñanza, en particular para abordar los problemas escolares o necesidades educativas especiales de origen multifactorial que prevalecen en los contextos educativos.

Por su parte, Atilano y López presentan una propuesta de intervención basada en la didáctica crítica para docentes de derecho en una universidad pública, con quienes se realizó un diagnóstico que develó que la mayoría de ellos parte de la experiencia en su campo laboral y, tradicionalmente, para la enseñanza del derecho se centran en la memorización y repetición de contenido.

Quintero y Arriaga identifican las características de la instrucción que reciben los estudiantes de preparatoria (bachillerato) abierta que en su mayoría son adultos con responsabilidades de trabajo y con dependientes económicos, con intereses distintos a los estudiantes comunes. Los autores reflexionan sobre las estrategias didácticas adecuadas para que los docentes puedan acompañar a estos estudiantes durante todo su proceso de aprendizaje.

A través del método de investigación-acción y el aprendizaje basado en proyectos, Olguín, Espinosa y Oliveros abordan la enseñanza de la danza folclórica en una escuela secundaria pública, en un entorno virtual de aprendizaje (EVA), de forma multidisciplinaria a través de un taller como intervención educativa. 
Finalmente, Álvarez, Lomeli y Figueroa presentan los resultados de una investigación-acción con aprendizaje cooperativo y el empleo del teléfono inteligente, realizada en clases a distancia en una universidad privada de la ciudad de Mexicali, Baja California, México. Se presenta las perspectivas de los alumnos y el docente, por medio de retroalimentaciones acerca de los aprendizajes realizados durante las clases.

Este libro representa un recorte de la realidad que viven los docentes y gestores educativos en el ámbito profesional de la docencia y los contextos educativos, expuesta a través de diversas propuestas de abordaje teórico-metodológico que guiarán a quienes se interesen en la metodología de intervención educativa como herramienta de transformación social, de construcción y transferencia del conocimiento.

(iD Julieta López Zamora

(iD) Dennise Islas Cervantes

(iD Ernesto Israel Santillán Anguiano 


\title{
Capítulo 1
}

\section{Interdisciplina, innovación y aprendizaje significativo. Posibles aplicaciones en educación superior}

\author{
Miguel Ángel Domínguez Cruz, Ernesto Israel Santillán Anguiano \\ y Reyna Isabel Roa Rivera
}

La interdisciplinariedad es considerada como un pilar importante para lograr romper con los límites del conocimiento; esta surgió de la necesidad de solucionar problemas complejos que las disciplinas por sí mismas no alcanzaban a responder, debido a la fragmentación del conocimiento que se suscita en la especialización de estas (Llano et al., 2016). Este problema de fragmentación fue expuesto desde la década de los setenta en un informe por la Organización para la Cooperación y el Desarrollo Económico (OCDE, 1972), donde académicos de diversos países acordaron la necesaria unificación del conocimiento para hacer más eficiente la resolución de problemas.

Tras analizar la importancia de la interdisciplinariedad para la construcción del conocimiento, en 1998, en la Declaración Mundial sobre la Educación Superior del siglo XXI se plantearon las directrices que le corresponden abordar a la Universidad, en las que se mencionan servir a la sociedad, eliminar la pobreza y el analfabetismo y ayudar a solucionar cualquier problema que pueda presentar la humanidad desde enfoques inter y transdisciplinarios (Organización de las Naciones Unidas para la Educación, la Ciencia y la Cultura [unEsCo], 1998). 
Hoy en día, cada vez más se encuentran enfoques interdisciplinarios en el contexto educativo, los cuales requieren trascender de una perspectiva simplista, que limita a la interdisciplinariedad al simple hecho de reunir a grupos de personas de diferentes disciplinas para dialogar o hacer algún proyecto en conjunto (Pombo, 2013). En cuanto a la educación para el 2030, esta debe permitir a sus estudiantes generar conocimientos interdisciplinarios, desde el diseño de los planes de estudio, debido a que existen conceptos claves dentro de cada área de conocimiento que pueden ser utilizados en otras diferentes (OCDE, 2019).

Para entender los niveles de interdisciplinariedad con los que se puede trabajar, Pombo (2013) planteó el uso de los prefijos multi o pluri, inter y trans como una progresión consecutiva que va desarrollando la desfragmentación de conocimiento entre las distintas disciplinas. Se entiende por pluri o multidisciplinario a la coordinación para continuar con la interdisciplinariedad, en el sentido de una combinación, y culminar con la transdisciplinariedad, es decir, la fusión de saberes que desarrollan una perspectiva holística del objeto de estudio.

El tema de la interdisciplina en la educación superior en México se impulsó por su capacidad de transformar la realidad social y educativa hacia las necesidades globales (Villa \& Mendoza, 2020). Las acciones que acompañaron la introducción del enfoque interdisciplinario dentro de las universidades del país fueron los troncos comunes, el incremento de colaboración con el sector productivo y contar con mayor involucramiento social (Villa \& Mendoza, 2020).

\section{Interdisciplina en el contexto educativo}

Con respecto a la interdisciplinariedad en la educación, resulta relevante entenderla desde una visión internacional, acorde con una educación global, y lograr establecer el currículo contemporáneo deseado. Se define 
al enfoque interdisciplinario desde el glosario del International Bureau of Education (IBE, 2013) como "un enfoque de la integración curricular que genera una comprensión de temas e ideas que atraviesan disciplinas y de las conexiones entre diferentes disciplinas y su relación con el mundo real" (p.32). Subrayando la importancia de combinar conceptos, metodologías y prácticas de dos o más disciplinas.

La Organización de Estados Iberoamericanos para la Educación, la Ciencia y la Cultura (OEI, 2017) realizó un informe de manera monográfica que abarca a Brasil, España y México, en el que se comprueba que las buenas prácticas de los directivos de instituciones educativas deben tener siempre presente la interdisciplinariedad, la multiculturalidad y la internacionalización como eje de sus acciones. La optimización de los procesos de enseñanza y aprendizaje se alcanzan con proyectos colectivos, la implicación de la comunidad y la visión del equipo directivo para el beneficio de la calidad escolar (OEI, 2017).

España, Zavala y Salinas (2017) llevaron a cabo una investigación de tipo cuantitativo y cualitativo que recopila información de tres centros educativos, respecto a las causas que no favorecen la realización de actividades interdisciplinarias entre sí. De acuerdo con estos autores, existe un interés latente de los docentes por realizar actividades interdisciplinarias, sin embargo, el diseño curricular y la poca flexibilidad de los centros educativos, obstaculizan el desarrollo de ambientes interdisciplinarios. Concluyen que es preciso el trabajo en equipo y la colaboración entre departamentos para eliminar las limitaciones que se presentan por querer implementar la interdisciplinariedad como parte de la cotidianidad.

Dentro del distrito Karakocan en Turquía, Aslan y Aybek (2020) realizaron una investigación cuantitativa con estudiantes de cuarto grado de primaria, que tuvo como objetivo analizar la eficacia de un programa 
interdisciplinario basado en educación multicultural. Según estos autores, hubo un progreso significativo en el pensamiento crítico por parte de los estudiantes participantes, por contar con una experiencia educativa interdisciplinaria y multicultural que los confrontara a defender sus puntos de vista respecto a las diferentes perspectivas de sus compañeros. Por otro lado, la tolerancia, la actitud democrática y el respeto por las emociones resultan ser aspectos altamente desarrollados en este tipo de ambientes educativos.

En el contexto latinoamericano, se efectuó un estudio en dos universidades ecuatorianas; Suarez, Martínez y Lara (2018) analizaron la organización y planificación de 15 proyectos de la carrera de Ingeniería en Sistemas y 12 proyectos de Ingeniería Industrial, arrojando como resultados la ausencia del trabajo interdisciplinario por parte de los docentes, lo que provocó barreras en el estudiante para entrelazar contenidos y prácticas con otras disciplinas. Concluyeron que el origen de dichas dolencias proviene por la desinformación de la interdisciplinariedad, el nivel de experiencia docente en el diseño microcurricular y la disposición del profesorado por relacionarse con otras disciplinas.

En Puerto Rico, Ortiz, Rivera y Díaz (2019) utilizaron la investigación-acción de carácter cualitativo para descubrir cómo el trabajo interdisciplinario se iba transformando en un trabajo transdisciplinario, que se expondría en escena como producto final. De tal manera que, en tiempos de bajo presupuesto, este tipo de actividades interdisciplinarias cuenta con la capacidad de fraccionar sus partes en módulos más económicos capaces de trasladarse a escuelas y comunidades diversas.

En México, desde una investigación documental con un método de intervención exploratoria, se planteó la fusión de técnicas escénicas y artísticas con la cultura científica, teniendo la finalidad de lograr rentabilidad financiera en compañías universitarias de teatro por medio de la 
interdisciplinariedad. Jiménez (2018) explicó que a pesar de los esfuerzos de sostenibilidad que se presentan en la investigación, sigue existiendo la debilidad de no contar con financiamiento permanente que pueda destinarse a producciones más completas, lo que llevó a la conclusión de la necesidad de adquirir conocimientos de diferentes áreas para encontrar nuevas formas de expresión que cautiven nuevos públicos y retengan a los actuales. Enfatizando la importancia de establecer redes entre lo formativo y lo profesional, con el propósito de vincular el conocimiento hacia la rentabilidad que requiere cualquier proyecto dentro de la universidad.

\section{Innovación parte del enfoque interdisciplinario}

Resulta de gran interés para la sociedad abordar la innovación dentro de la educación, debido a que representa una ventana hacia una buena calidad de vida, como propone la Red de Innovación Educativa (RIE, 2018), la innovación tiene el propósito de mejorar la calidad de vida del mayor número de personas desde la aportación de nuevas ideas que puedan transformarse en procesos, productos o servicios. A su vez, el nuevo panorama de la educación superior requiere de la creatividad de los docentes, el apoyo de las instituciones y la colaboración interdisciplinar para la construcción del nuevo conocimiento que se necesita en el siglo XXI (RIE, 2018).

De acuerdo con las tendencias actuales de automatización, se estima que en las próximas dos décadas un $47 \%$ de los trabajos en Estados Unidos podrían perderse, lo que obliga a una transformación de las universidades para desarrollar los conocimientos y habilidades que sean de utilidad para la sociedad en un futuro no tan lejano (RIE, 2018). Para prevenir dicha situación, la OCDE (2017) reconoció al conocimiento disciplinar e interdisciplinar, junto con las habilidades sociales y otros aspectos, 
como parte fundamental de los cambios necesarios para la educación que pretende tener relevancia dentro de los años venideros.

Para entender la interacción que existe entre la innovación y la educación, Lašákováa et al. (2017) presentaron un estudio de caso que analiza a diez universidades europeas respecto a las barreras e impulsores de la innovación en la educación superior, utilizando un enfoque ilustrativo y descriptivo. Estos autores señalaron que el entorno organizacional, el desinterés por la innovación y la falta de habilidades en las tecnologías de la información y comunicación representan los tres principales obstáculos de innovación dentro de la educación superior. Mientras que en los impulsores de la innovación se encuentran: (a) una cultura de apertura que direcciona sus esfuerzos en crear equipos interdisciplinarios que cuenten con lugares de trabajo transversales especializados y (b) una gestión consciente de la innovación.

En la Universidad de Southampton del Reino Unido, se efectuó una investigación-acción que tuvo como propósito promover la transformación curricular y profesional en la educación hacia el desarrollo sostenible, a través de un grupo interdisciplinario conformado por cinco docentes universitarios de diferentes áreas de conocimiento. Según Cebrián (2020) para generar conciencia de nuevas prácticas que se encaminen a un aprendizaje transformativo, existe la necesidad de trabajar interdisciplinariamente con el objetivo de apoyar la reflexión crítica. Volviéndose indispensable la creación de estrategias colaborativas que cuestionen las propuestas curriculares y los modelos mentales que se forman en cada área de conocimiento.

La innovación y la interdisciplinariedad están en constante diálogo con la creatividad, para hacer evidente dicha convivencia se realizó, por medio del paradigma positivista y el método deductivo-lógico, un análisis de la relación que existe entre la interdisciplinariedad y el grado de 
innovación que tienen las ideas de negocio, realizadas por estudiantes de la Universidad Simón Bolívar. Contreras et al. (2017) comprobaron, a través del índice de variación cualitativa, que las ideas de negocio con mayor innovación e impacto social provienen de grupos con mayor nivel de interdisciplinariedad; a la par, se confirmó que los problemas complejos deben abordarse con propuestas integrales, ya que estas generan mayor interés para su realización.

Transitando al territorio mexicano, en el Programa en Ciencias Sociales de la Universidad de Sonora, se llevó a cabo una investigación con una metodología de enfoque mixto integrado con inclinación hacia lo cualitativo, con el propósito de analizar los procesos de innovación en la formación interdisciplinaria de los estudiantes de maestría y doctorado. Esqueda y León (2017) indicaron que llevar a la práctica la colaboración entre distintas disciplinas, permite generar conocimientos innovadores que representan una aportación trascendental y refrescante para la sociedad. Además, los estudiantes participantes de la investigación manifestaron que la formación interdisciplinaria no solo enriquece sus proyectos de posgrado, sino también aspectos personales que logran cambiar gradualmente el entendimiento de su entorno.

\section{Colaboración interdisciplinaria como aprendizaje significativo}

El proceso que llevan las personas para desarrollar un aprendizaje significativo es a través de redes conceptuales que se pueden utilizar en diferentes situaciones para la resolución de problemas en forma creativa, esto sucede por el hecho de conectar experiencias personales que se orientan con la práctica (IBE, 2013). Siendo el aprendizaje significativo un proceso lento y escalonado que no se produce linealmente, este requiere de un intercambio de significados que toman presencia con el paso del tiempo (Contreras, 2016). 
Al explorar el aprendizaje significativo, Hart (2019) realizó un estudio que revisa a profundidad una gran variedad de artículos de Estados Unidos y otros países que presentan casos de estudio relacionados al aprendizaje multi, inter y transdisciplinario, los cuales se usan como referencia para realizar un análisis que los relacione con la empleabilidad de Licenciaturas en Ciencias. Hart (2019) concluyó que el aprendizaje interdisciplinario basado en proyectos es un método para desarrollar habilidades de empleabilidad, pero existe la posibilidad de generar una disminución de conocimientos de la disciplina principal. Asimismo, enfatizó que no tiene que ser de esta manera, si se diseña el currículo alineado en todos sus ejes. Además, los medios tradicionales de educación no permiten enseñar las habilidades de empleabilidad deseadas, estas se desarrollan con el tiempo mediante experiencias prácticas.

Para comprender la perspectiva de los estudiantes de la Universidad de Arizona sobre los cursos interdisciplinarios centrados en una idea, Baker y Pollard (2020) indicaron que los estudiantes muestran gran interés en la educación interdisciplinaria y afirmaron conocer la importancia que tiene el desenvolverse en ambientes interdisciplinarios para su aprendizaje. Con la evolución de las estructuras curriculares de las universidades hacia propuestas más integradoras, se logra contribuir al aumento de capacidades analíticas que ayudan a la descomposición de problemas cada vez más complejos (Baker \& Pollard, 2020).

La importancia que tiene el trabajo colaborativo se demuestra en las cifras del fortalecimiento, que tuvieron los procesos nacionales de desarrollo de los países latinoamericanos, por el intercambio de experiencias y conocimientos (Secretaría General Iberoamericana, 2018). En este proceso de intercambio es necesario un entendimiento profundo de lo que se está aprendiendo, por lo tanto, desde el contexto mexicano que es desde donde se realizan las aportaciones de este capítulo, se define al 
aprendizaje significativo como "el andamiaje entre los aprendizajes ya adquiridos y los que están por adquirirse; lo cual facilita la relación de conocimientos anteriores con lo que se aprenderá" (Secretaría de Educación Pública [SEP], 2019).

Simón (2015) señaló en un estudio exploratorio-descriptivo que existía la percepción en el egresado en Ciencias Empresariales que su formación multidisciplinaria resultaría ventajosa sobre las carreras tradicionales en relación con la empleabilidad, provocando gran optimismo al momento de buscar trabajo. Sin embargo, en la búsqueda del primer trabajo, los egresados se toparon con el problema de que los empleadores desconocían la carrera, lo que dificultaba su inserción laboral y en sus búsquedas posteriores de oportunidades laborales nunca encontraron ofertas de trabajo dirigidas directamente a su licenciatura. Esta incertidumbre por la que pasan los estudiantes de las licenciaturas híbridas puede postergar la implementación de carreras similares en el país.

\section{Conclusiones}

Después de la revisión de diferentes perspectivas que abogan por la implementación de la interdisciplinariedad dentro de la educación, se concluye que implementar este tipo de enfoques en el ámbito educativo es de suma importancia, puesto que, a pesar de que en la sociedad se pueda dividir el conocimiento en diferentes disciplinas, la interdisciplinariedad sirve de recordatorio respecto a cómo el intercambio de conocimiento que se considera especializado ha sido una pieza clave para el progreso científico, gracias a la colaboración y la transferencia de información de unos a otros, debido a que todo es parte del mismo sistema.

Por otra parte, la innovación en la educación debe implementar cambios constantes de todo lo establecido, incluyendo prácticas, rutinas, reglas y convivencias que puedan contribuir al desarrollo de ideas 
sostenibles capaces de llevarse a cabo. Además, el desarrollo de aprendizajes significativos provenientes de la confrontación de modelos mentales que han sido construidos desde diferentes disciplinas se transforma en la base que sustenta la incorporación de la interdisciplinariedad en la educación.

Para finalizar, dentro de la interdisciplinariedad constantemente se genera un círculo virtuoso entre la innovación, el emprendimiento, el trabajo en equipo y los aprendizajes significativos. Cada proyecto que involucra enfoques interdisciplinarios responde ante la necesidad de conseguir cierto nivel de innovación, que sea capaz de incentivar el emprendimiento por el simple hecho de generar soluciones creativas y sostenibles, mientras que desarrolla aprendizajes significativos por trabajar en equipo. 
Capítulo 1

\section{Referencias}

Aslan, S., \& Aybek, B. (2020). Testing the effectiveness of interdisciplinary curriculum-based multicultural education on tolerance and critical thinking skill. International Journal of Educational Methodology, 6(1), 43-55. https://doi.org/10.12973/ijem.6.1.43

Baker, M., \& Pollard, J. (2020). Student Learning in Interdisciplinary TeamTaught Courses Centered on a “Big Idea”. Journal of Interdisciplinary Studies in Education, 9(2), 338-360. https://www.ojed.org/index. $\mathrm{php} / \mathrm{jise} / \mathrm{article} / \mathrm{view} / 2273$

Cebrián, G. (2020). La educación para el desarrollo sostenible en el currículum universitario: una investigación-acción cooperativa con profesorado. Revista iberoamericana de educación superior, 11(30), 99-114. https://doi.org/10.22201/iisue.20072872e.2020.30.590

Contreras, F. A. (2016). El aprendizaje significativo y su relación con otras estrategias. Horizonte De La Ciencia, 6(10), 130-140. http://revistas. uncp.edu.pe/index.php/horizontedelaciencia/article/view/364

Contreras, J. C., Wilches, S. Y., Graterol, M. E., \& Bautista, M. J. (2017). Educación Superior y la Formación en Emprendimiento Interdisciplinario: Un Caso de Estudio. Formación universitaria, 10(3), 11-20. https://doi.org/10.4067/S0718-50062017000300003

Esqueda, M. F., \& León, G. A. (2017). Innovación, investigación y educación interdisciplinaria en México. En R. Roig-Villa (Ed.), Investigación en docencia universitaria. Diseñando el futuro a partir de la innovación educativa (pp. 513-519). Octaedro. http:// rua.ua.es/dspace/handle/10045/71155

Hart, J. L. (2019). Interdisciplinary project-based learning as a means of developing employability skills in undergraduate science degree programs. Journal of Teaching and Learning for Graduate Employability, 10(2), 50-66. https:/doi.org/10.21153/ jtlge2019vol10no2art827 
International Bureau of Education. (2013). Glossary of Curriculum Terminology. http://www.ibe.unesco.org/en/document/glossarycurriculum-terminology

Jiménez, P. S. (2018). Compañías universitarias interdisciplinarias rentables: Laboratorio Teatral Látex-UAQ. Revista Iberoamericana Para La Investigación y el Desarrollo Educativo, 9(17), 837-864. https://doi.org/10.23913/ride.v9i17.407

Lašákováa, A., Bajzíkováa, L., \& Dedzeb, I. (2017). Barriers and drivers of innovation in higher education: Case study-based evidence across ten European universities. International Journal of Educational Development, 55, 69-79. https://doi.org/10.1016/j. ijedudev.2017.06.002

Llano, L., Gutiérrez, M., Stable, A., Núñez, M., Masó, R. M., \& Rojas, B. (2016). La interdisciplinariedad: una necesidad contemporánea para favorecer el proceso de enseñanza aprendizaje. MediSur, 14(3), 320327. http://scielo.sld.cu/scielo.php?script=sci_arttext\&pid=S1727897X2016000300015

Organización de las Naciones Unidas para la Educación, la Ciencia y la Cultura. (1998). Declaración Mundial sobre la Educación Superior en el siglo XXI: Visión y Acción. https://unesdoc.unesco.org/ ark:/48223/pf0000113878_spa

Organización para la Cooperación y el Desarrollo Económicos. (1972). Interdisciplinarity: Problems of Teaching and Research in Universities. https://eric.ed.gov/?id=ED061895

Organización para la Cooperación y el Desarrollo Económicos. (2017). Marco de Evaluación y de Análisis de PISA para el Desarrollo: Lectura, matemáticas y ciencias, Versión preliminar. OECD Publishing. https://www.oecd.org/pisa/aboutpisa/ebook\%20-\%20 PISA-D\%20Framework_PRELIMINARY\%20version_SPANISH.pdf 
Organización para la Cooperación y el Desarrollo Económico. (2019). Conceptual learning framework. KNOWLEDGE FOR 2030. https:// www.oecd.org/education/2030-project/teaching-and-learning/ learning/knowledge/Knowledge_for_2030_concept_note.pdf

Organización de Estados Iberoamericanos para la Educación, la Ciencia y la Cultura. (2017). Miradas sobre la educación en Iberoamérica. Desarrollo profesional y liderazgo de directores escolares en Iberoamérica. Grafilia.

Ortiz, B. M., Rivera, V., \& Díaz, L. M. (2019). El Nanocirco: un diseño interdisciplinario para la divulgación y enseñanza de la nanociencia y la nanotecnología. Revista Eureka sobre Enseñanza y Divulgación de las Ciencias, 16(2), 2301. https://revistas.uca.es/index.php/ eureka/article/view/4423

Pombo, O. (2013). Epistemología de la interdisciplinariedad. La construcción de un nuevo modelo de comprensión. INTER DISCIPLINA, 1(1), 21-50. http://revistas.unam.mx/index.php/inter/ article/view/46512

Red de Innovación Educativa. (2018). Perspectivas de la innovación educativa en universidades de México: Experiencias y reflexiones de la RIE 360.http://rie360.mx/images/pagina_principal/imagenes_ carrusel_noticias/03_libro_rie360/perspectivas-de-la-innovacion_ ebook.pdf

Secretaría de Educación Pública. (2019). ACUERDO número 24/12/19 por el que se emiten las Reglas de Operación del Programa Desarrollo de Aprendizajessignificativos deEducaciónBásicaparaelejerciciofiscal 2020. Diario Oficial de la Federación, DOF 29-12-2019. https://www. dof.gob.mx/nota_detalle.php?codigo=5583046\&fecha=29/12/2019

Secretaría General Iberoamericana. (2018). Informe de la cooperación sur-sur en Iberoamérica 2018. https://www.informesursur.org/ 
Simón, J. D. (2015). Las expectativas de búsqueda del primer empleo de universitarios con formación híbrida: El caso de una universidad pública mexicana. Cuadernos de Investigación Educativa, 6(2), 33-49. https://revistas.ort.edu.uy/cuadernos-de-investigacioneducativa/article/view/35

Suarez, N., Martínez, A., \& Lara,D.G. (octubre, 2018). Interdisciplinariedad y proyectos integradores: un desafío para la universidad ecuatoriana. Perspectiva Educacional. Formación de Profesores, 57(3), 54-78. http://www.perspectivaeducacional.cl/index.php/peducacional/ article/view/700

Villa, J. C., \& Mendoza, R. M. (2020). Criterios para definir el carácter interdisciplinario de diseños curriculares universitarios. INTER DISCIPLINA, 8(20), 167-189. http://www.revistas.unam.mx/index. $\mathrm{php} /$ inter/article/view/71977

Zavala, C. M., \& Salinas, J. R. (julio, 2017). La interdisciplinariedad en el aula de educación secundaria: una investigación a través de la opinión del profesorado de las áreas de Música, Lengua Castellana y Literatura, y Ciencias Sociales. European Scientific Journal, 13(19), 281-291. https://doi.org/10.19044/esj.2017.v13n19p281 


\section{Capítulo 2}

\section{Dificultades de aprendizaje e inclusión: un análisis desde la neuroeducación}

Elena Hatty Jiménez Pérez, Dennise Islas Cervantes

y Leidy Hernández Mesa

Las dificultades de aprendizaje son un tema abordado desde distintas disciplinas para referirse a patrones de conductas que se caracterizan por determinados problemas en el aprendizaje de la lectoescritura y las matemáticas. Asimismo, forman parte de los problemas escolares o necesidades educativas especiales de origen multifactorial que prevalecen en los contextos educativos. La atención a estas dificultades significa un reto para la pedagogía inclusiva que busca estimular un clima escolar positivo y condiciones de aprendizaje favorables. En este sentido, el presente estudio tiene como objetivo analizar a partir de fundamentos psicopedagógicos las dificultades específicas del aprendizaje y su tratamiento bajo principios inclusivos, así como los aportes neurocientíficos a las ciencias de la educación para su atención.

Dificultades de aprendizaje en aulas inclusivas Dificultades de aprendizaje, una aproximación a su conceptualización El término dificultades de aprendizaje (DA) es utilizado para caracterizar determinadas manifestaciones que presentan niños y adolescentes en 
edad escolar. En este sentido, forman parte del objeto de estudio de la educación especial, la psicopedagogía, la psicología y la educación en sentido general como respuesta a su preocupación por el proceso de aprendizaje. En la literatura pueden aparecer dentro de las necesidades educativas especiales (NEE) como dificultades específicas del aprendizaje o trastornos de aprendizaje. Ello para referirse únicamente a los estudiantes que tienen una o varias manifestaciones que demuestran dificultad en el área de las matemáticas o la lectoescritura (Aguilera \& García, 2004). Sin embargo, es preciso destacar que se hace uso del término para referirse a cualquier dificultad notoria en el desempeño escolar sin que esto implique un trastorno y, en correspondencia, un diagnóstico y un tratamiento.

Los hitos históricos que marcan las DA demuestran el recorrido significativo que han mostrado a lo largo de la historia, así como el significado que se le otorga desde su concepción como etiqueta diagnóstica para definir el defecto, su tránsito dentro de las antes mencionadas NEE hasta su asociación y respuesta a la diversidad en las prácticas educativas. En la búsqueda de un consenso en cuanto a su definición es preciso hacer mención a la National Joint Committee on Learning Disabilities (NJCLD, 1990), quien fuera la primera en aportar una definición conceptual —Kirk en 1962 aportó su propia terminología al respecto (Aguilera, 2004)—, la cual es justificada a partir de los preceptos que, fundamentados en la psicología, demuestran la necesidad de entender la manifestación y los patrones repetidos con la intención de encontrar un diagnóstico, para a partir de ello atenderlo. Debido a esa necesidad surge en principio la conceptualización de las DA, aunado a la intención de atender las características presentes, prevalencia y posibles causas, pero desde la base de una definición preexistente que ayude en gran medida al entendimiento del problema y sus bases para el futuro tratamiento.

Como resultado se incorporan al debate científico las DA desde 1962 con los aportes al concepto por parte de Kirk, quien las reconoce como 
un "retraso en el desarrollo en uno o más de los procesos del habla, lenguaje, lectura, escritura, aritmética” (como se citó en Hammill, 1990, p.75). Sin embargo, es válido destacar las nuevas miradas que se desprenden de esta, una de las primeras definiciones propuestas en aquellos años. Ello en consecuencia con el discurso inclusivo que se defiende en la actualidad, que lejos de segregar y estigmatizar a los estudiantes apoye la diversidad como norma.

En principio, también se le agregó al concepto su relación con los desórdenes neurobiológicos y la marcada diferencia entre el desempeño académico alcanzado por unos estudiantes en comparación con otros, lo cual no significa un retraso mental presente cuando se está ante las DA, aun cuando la comorbilidad pueda ser significativa. Por lo tanto, cuando se hace mención a las DA, se entienden como manifestaciones caracterizadas por dificultades específicas en áreas de la aritmética como es el cálculo, el razonamiento matemático, así como en el habla, la lectura y la escritura, las cuales pueden estar asociadas a una disfunción neurobiológica, provocada o no por determinados trastornos, mostrando así su comorbilidad con trastornos del neurodesarrollo, entre otros (Fourneret \& Da Fonseca, 2019; Maldonado, 2021; Mejía \& Cifuentes, 2015). Por otra parte, no significa asociación o predicción con el coeficiente intelectual predominante en los niños y adolescentes que presentan DA, sino una o varias habilidades no desarrolladas para cumplir determinadas tareas correspondientes a su etapa de desarrollo cognitivo, lo cual puede interferir en el cumplimiento del logro académico respecto a su edad escolar.

Por lo anterior, su conceptualización tiene un marcado interés por los autores que dedican sus estudios a la educación especial, la diversidad y la inclusión. Además, es debatido por organismos internacionales y nacionales, los cuales promueven una cultura de la definición en búsqueda del consenso en el discurso como primer paso para diagnosticar y 
atender desde las prácticas inclusivas que se defienden en la educación (Aránega, 2019; López, 2017).

\section{Problemas escolares}

La vida en la escuela conlleva aprendizaje y un sin fin de retos. La escuela plantea la exposición a nuevas situaciones que, de acuerdo con las características, recursos y personalidad de cada individuo, será más sencillo o no afrontarlas y, por tanto, resolver. En los contextos educativos son frecuentes los problemas escolares, los cuales son asociados a las dificultades de aprendizaje, no todos considerados como graves, ya que no se encuentra comprometida la capacidad intelectual ni presentan algún déficit, sino que estos se suscitan por factores externos como son los problemas familiares o sociales que, al ser atendidos y brindar un adecuado seguimiento, se logran resarcir en un corto tiempo y el estudiante regresa a un desempeño y ritmo regular y esperado, pero cuando los problemas escolares persisten pueden conllevar al fracaso escolar afectando varias dimensiones de vida de la persona (personal y social).

En este tenor, Romero y Lavigne (2005) presentan una caracterización de las dificultades de aprendizaje que son provocados por los problemas escolares:

a. Dificultades de aprendizaje no específicas, limitadas en tiempo y en áreas, suelen presentarse en el nivel escolar de secundaria, pero pueden agudizarse en secundaria.

b. Problemas leves, reversibles, relacionados a contenidos y materias concretas, pueden variar en los estudiantes y sin razón aparente para el problema.

c. Problemas que se presentan de manera puntual relacionados a una materia, contenidos o circunstancias escolares concretos (rechazo, déficits o poca adaptación a métodos de enseñanza). Este tipo de 
estudiantes presentan desarrollo intelectual e historial académico normalizados.

d. Problemas que se presentan de forma ocasional relacionada con tareas y contenidos. Puede observarse falta de motivación, indisciplina, expectativas negativas de logro o inadaptación escolar y no presentan alteraciones o déficits psicológicas.

e. Afectación de modo leve y puntual al aprendizaje de conocimientos, de procedimientos (e. g., estrategias de comprensión lectora y escrita) y del tiempo de logro de dichos aprendizajes (e. g., deficiencias en la organización y distribución del tiempo) (Fernández, 2005; Romero \& Lavinge, 2005; Vallejo, 2010).

Lo anteriormente descrito, se diferencia de las dificultades de aprendizaje, ya que se resuelven con facilidad; basta el apoyo y seguimiento de un asesor o tutor, pero sin una intervención psicopedagógica especializada; por ello, los problemas son considerados leves, ya que sus consecuencias pueden ser atendidas y subsanadas en un corto tiempo, si son detectadas y atendidas a tiempo.

La presencia de estos problemas escolares trae como consecuencia un bajo rendimiento en los estudiantes; de no detectarlos y atenderlos a tiempo se agravan, afectando a estudiantes y centros escolares. Puede afirmarse también que los problemas escolares son multifactoriales, según Ruíz (2013), se puede presentar por una diversidad de causantes que afectan el rendimiento escolar; para explicarlo, plantea el modelo ecológico multifactorial, en el cual se clasifican las condicionantes del rendimiento escolar en factores personales, familiares, escolares y sociales, los cuales se caracterizan por las actitudes hacia el ambiente y los sentimientos y pensamientos que provocan en el estudiante. 
Otro de los aspectos relacionado con problemas escolares es la asistencia; según Moyano et al. (2017) puede presentarse miedo por asistir, absentismo sin autorización, abandono y bajo rendimiento. El miedo puede ser generalizado o hacia alguna persona o situación en particular, se pueden presentar síntomas físicos, por lo que debe prestarse atención. El absentismo y el abandono conlleva una conducta reiterada para no continuar en ella, lo que incrementa esta posibilidad es que el niño o adolescente presente problemas como, por ejemplo, poco éxito en actividades escolares o bajo rendimiento académico.

En este contexto, términos como bajo rendimiento, fracaso y abandono escolar se hacen presentes; es muy importante que todos los actores educativos comprendan su impacto, para ello, Jadue (2002) analizó factores psicosociales que predisponen estas condiciones y afirmó que quienes presentan problemas conductuales y de rendimiento presentan leves alteraciones en su desarrollo cognitivo, afectivo o psicomotor.

Por lo que, supeditar la enseñanza a la norma, pone en desventaja a estudiantes que presentan condiciones específicas y, por lo tanto, los sitúa en condición de riesgo, es decir, al no ser consideradas y comprendidas las condiciones personales o las circunstancias contextuales que rodean a los estudiantes. Las expectativas escolares de los padres de familia y de los docentes sobre lo que se espera como una conducta adecuada, determinará en gran medida el nivel de tolerancia hacia los problemas que presenten los estudiantes y de ello también dependerá la urgencia con la que debe atenderse o tratarse. Los problemas emocionales y conductuales conllevan dificultades para aprender, por lo que es necesario determinar si las causas son orgánicas o psíquicas para un adecuado diagnóstico, pero a nivel escolar, de manera somera, se espera que todos se comporten y rindan de manera semejante. 
Las alteraciones en las habilidades sociales o emocionales afectan la conducta y aprendizaje, lo que conlleva al bajo rendimiento, fracaso y deserción escolar. Un manejo adecuado de la competencia emocional en el estudiante les permitirá comprender situaciones de su propia vida y manejar tareas diarias como aprender, resolver, adaptarse y establecer relaciones personales y sociales. La comprensión de la importancia de la dimensión afectiva en los centros educativos y el profesorado permitirá el manejo de este tipo de alteraciones y, así, las escuelas se convertirán en espacios con igualdad de oportunidades para progresar, crecer y desarrollarse (Jadue, 2002; Klinger et al., 2011). En consideración, la pedagogía inclusiva intenta desarrollar en los docentes las competencias para llevar a cabo prácticas educativas éticamente responsables con la equidad.

\section{Pedagogía inclusiva}

Hablar de problemas escolares y DA implica necesariamente entender y aceptar la inclusión como factor clave que promueve la diversidad en la educación. Es a partir de estos análisis - necesarios ante la aceptación de la condición inherente del ser humano diferente- que surge la pedagogía inclusiva, sobre todo en el marco de la formación profesional docente. Pero ¿qué significa pedagogía inclusiva? Significa una línea de acción que contribuye desde su concepción a la preparación de docentes competentes para llevar a cabo procesos de enseñanza y aprendizaje, considerando a cada uno de sus estudiantes y aceptando sus necesidades y potencialidades (García-González et al., 2018). Lo anterior, en congruencia con el cumplimiento de los principios de equidad y calidad en la educación, sea cual fuera el nivel.

La atención diferenciada, el respeto a los ritmos de aprendizaje, la identificación y la atención a las necesidades educativas especiales, 
las DA específicas y no específicas dentro del proceso de enseñanza y el aprendizaje en contextos escolares convierten la labor docente en un desafío. Es entonces donde la pedagogía inclusiva brinda las herramientas y competencias necesarias para que el docente intervenga en sus prácticas profesionales de manera oportuna. La estrategia está encaminada a aportar conocimientos pertinentes sobre las características que presentan todos los estudiantes, sobre el logro de sus aprendizajes, por encima de cualquier dificultad, déficit, trastorno o incapacidad. La pedagogía inclusiva intenta demostrar que los límites ante lo distinto y desconocido obstaculizan los procesos de crecimiento y desarrollo, haciendo notorio la segregación, aún sin una intención marcada.

Esta pedagogía muestra un enfoque comprometido con la atención al aprendizaje de los estudiantes, basada en una didáctica adaptada a cada uno, sin que eso suponga un desgaste de recurso y tiempo en su elaboración para que se ajuste a las NEE. Florian (2015) se considera uno de los pioneros de la pedagogía inclusiva, al aplicarla en contextos educativos muestra su preocupación por las limitaciones en la enseñanza y el aprendizaje de los niños con NEE, marcadas en el estigma creado en la comunidad de docentes, ante la creencia de que necesitan una atención diferente que corresponda a sus diferencias individuales.

Por tanto, la pedagogía inclusiva comienza por enfrentar la perspectiva del desconocimiento hacia las particularidades de cada necesidad. Surge para dar respuesta a las prácticas educativas inclusivas con fundamento teórico y práctico, promoviendo en sí misma las concepciones de cada NEE y, con ellas, sus manifestaciones en contextos escolares, la variabilidad dependiendo del sujeto y lo impredecibles que pueden llegar a ser. En este sentido, apuesta por cambios centralizados desde la política de las instituciones educativas hasta la concepción y manejo de las dificultades particulares por parte de grupos y maestros. 
En consecuencia, surge la promoción de las condiciones para enfrentar una educación libre de desigualdades y exclusión (encubiertas o no), así como la formación y capacitación docente respecto a la didáctica basada en el respeto y la satisfacción de necesidades, desde el reconocimiento a los logros escolares que pueden o no ser alcanzados por los estudiantes. Por lo tanto, la concepción de que la atención especializada es objeto y campo de estudio de un solo profesional de la educación dígase psicopedagogo, psicólogo escolar- queda obsoleta en tiempos actuales, donde el conocimiento de las dificultades, el diagnóstico, sus bases, la reeducación y las políticas públicas son actualizados responsablemente.

\section{Bases neurobiológicas de las dificultades de aprendizaje}

El estudio de la neurobiología de las DA tiene sus bases en el área de las neurociencias, que a través de sus distintos campos disciplinares y el desarrollo científico-tecnológico ha podido demostrar con mayor exactitud un mapeo cerebral y sus funcionalidades en estudios de actividad cerebral. Las neurociencias cognitivas y la neuropsicología a través de las técnicas de neuroimagen demuestran la funcionalidad de los procesos cognitivos, donde el aprendizaje y sus trastornos quedan expuestos a análisis. Si bien es cierto que el cerebro actualmente es considerado el órgano del cuerpo humano de mayor complejidad, en los últimos años, el conocimiento y descubrimiento de este va en aumento.

El aprendizaje es un proceso que, en principio, se da a nivel cerebral y fisiológico, debido a la actividad asociativa entre células o, lo que es igual, las conexiones neuronales a través de la sinaptogénesis. Esto significa que sus manifestaciones tienen bases neuronales que expresan su funcionalidad mediante mecanismos de orden anatomofisiológico determinantes en el aprendizaje. Ejemplo de ello, lo demuestra la memoria 
y su sistema categórico, siendo esta la encargada de retener, almacenar y codificar ese conocimiento que el proceso de aprendizaje adquiere; lo cual permite la recuperación de la información para comprender nuevos conocimientos e influir en la conducta.

Todo ello se explica desde el principio de Hebb que expone la comunicación entre las neuronas y la excitación y activación asociada a la cognición. El cerebro está en constante aprendizaje y es demostrado mediante el proceso de plasticidad cerebral o neuroplasticidad, hito que marcó las neurociencias y revolucionó hallazgos del cerebro antes desconocidos o interpretados desde otras perspectivas. Este mecanismo demostró que el aprendizaje va a estar determinado por la interacción de factores genéticos, fisiológicos y ambientales; que está distante de ser un proceso estático sin evolución, que va a desarrollarse dentro de determinados periodos críticos del desarrollo como se creía en algún momento en el estudio del cerebro. Así como se localizan bases neurobiológicas que explican el aprendizaje y ayudan a comprender cómo se da y su relación con los procesos cognitivos en consonancia con el ambiente, también la neuropsicología y su carácter transdisciplinar como ciencia dedica especial atención a la comprensión de las DA desde sus bases cerebrales. La atención en este sentido está dada hacia los trastornos de aprendizaje clasificados dentro de los trastornos del neurodesarrollo, según el Manual diagnóstico y estadístico de los trastornos mentales, DSM5 (APA, 2014).

Estos trastornos, específicos por sus particularidades, se caracterizan por un marcado sustrato genético, biológico y neuronal con localizaciones en el sistema nervioso central, presentando anomalías o disfunciones en este. La dislexia se presenta como el trastorno que en principio aportó a la neuropsicología estudios descriptivos y correlacionales que, más adelante, dieron respuesta a anormalidades neuronales y sus conse- 
cuencias; lo cual es provocado por la relación entre las áreas cerebrales encargadas del lenguaje y sus conductas anormales manifestadas en la actividad cognoscitiva de la lectura.

Los defectos cerebrales del trastorno son notorios y se localizan en áreas específicas del hemisferio derecho e izquierdo y el tálamo, mostrando menor activación cortical durante el ejercicio de la lectura. El cuerpo calloso demuestra su tamaño significativamente menor en sujetos con este trastorno. Estas anomalías son estudiadas a través de la imagenología, mostrando diferencias en estructura y funcionalidad en sujetos disléxicos respecto a los que no presentan estas características (Ríos \& Lopez, 2017). Aunado a ello, se realizan estudios de correlación con pacientes que presentan disgrafía, que generalmente acompaña a la dislexia y sus dificultades, encontrándose un mayor número de investigaciones sobre esta última. La primera puede ser vista como una dificultad más, que comparte diagnóstico y elementos causales (Scrich et al., 2017).

Por otra parte, la discalculia — no tan prevalente como la dislexiatambién muestra un sustrato neuronal que ayuda a comprender sus manifestaciones en el aprendizaje del cálculo y las matemáticas en general. Los estudios neuropsicológicos al respecto explican la asociación del trastorno con irregularidades en la "memoria, en el manejo espacial y en las habilidades lingüísticas” (Roselli \& Matute, 2011, p.127). Algunas investigaciones (Geary, 2011; Keeler \& Swanson, 2001) han demostrado la tesis sobre una relación significativa entre la discalculia y el déficit cognitivo en la memoria de trabajo y la memoria semántica, a través de la aplicación de pruebas de memoria con y sin dígitos numéricos.

Las habilidades visuoespaciales y su correlación con las habilidades matemáticas han sido otra de las causales que explican algunos estudios en población con discalculia. Sin embargo, se puede asumir que 
estas hipótesis, que buscan comprobar que las deficiencias cognitivas son predictoras de la discalculia, son resultado de datos en muestras específicas, lo cual no necesariamente implica inferir que son condiciones distintivas del trastorno.

Al respecto, Castro-Cañizares et al. (2009) reconocen que "si bien el deterioro de estos procesos afecta el procesamiento numérico, las relaciones entre estas habilidades de propósito general y el rendimiento matemático necesitan una futura clarificación” (p.144). Es decir, son análisis no desestimados en su totalidad sino resultados que deben ser cuidadosamente presentados y aprobados en materia científica.

En la actualidad, se reconoce aún la necesidad de estudios de neuroimágenes específicos, aplicados en grandes poblaciones, que se encarguen de encontrar patrones neurofuncionales que ayuden a explicar estos trastornos. La discalculia del desarrollo $(D D)$ encuentra menor cantidad de investigaciones de orden neurobiológico y su asociación con la cognición numérica. Sin embargo, hoy se confirma la hipótesis sobre la relación entre las dificultades del aprendizaje de la matemática con daños de conectividad anatómica cerebral (Estévez et al., 2014).

\section{Dificultad específica en el aprendizaje de las matemáticas. Discalculia} Las dificultades en el aprendizaje están relacionadas con aptitudes académicas y, por ende, interfieren en el rendimiento académico. La discalculia es una dificultad específica, el término se utiliza para caracterizar a niños, adolescentes y adultos que presentan dificultades en el aprendizaje de operaciones aritméticas, como es el cálculo y los problemas de procesamiento numérico, así como el orden y la forma que podemos ver reflejado en distintas áreas de las matemáticas. La discalculia, al unirse con la dislexia, afecta la resolución de problemas matemáticos, ya sea a nivel escolar o en contextos reales, así como el razonamiento lógico matemático. 
La discalculia tiene una prevalencia que oscila entre 2.5 y $6.4 \%$; sin embargo, los datos provienen del análisis de prevalencia en Inglaterra, Israel, Alemania, India, Grecia y Cuba (Estévez et al., 2014). Es un trastorno del neurodesarrollo que se pone de manifiesto en la edad escolar y puede afectar, además de su rendimiento académico, su conducta y su inserción social. Según Benedicto-López y Rodríguez-Cuadrado (2019), "la discalculia es una dificultad específica para el aprendizaje de la aritmética independiente de la inteligencia y la instrucción, con base neurobiológica y tentativamente genética (p.3). Por su parte, Torresi (2020) identifica las semejanzas y diferencias entre lo que se reconoce como dificultad en el aprendizaje matemático y la discalculia, entendiéndose la primera a partir de diversas causales como "bajo desempeño en tareas aritméticas”, lo cual puede estar asociado a "déficit en alguno de los procesos cognitivos [...] por ansiedad matemática, fobia escolar, motivación, causas pedagógicas” (p.137). Por otro lado, defiende su concepción de discalculia a partir del sustrato neurobiológico que la caracteriza y su marcada dificultad en el sentido numérico. Al respecto, en el DSM-5 se reconoce las dificultades en las matemáticas que deben predominar para estar en presencia del trastorno:

a. Dificultad en el sentido numérico (al momento de escribir un número, al representar cantidades, significado numérico, orden numérica, relaciones entre número-cantidades, conceptos aritméticos propios que están en las matemáticas y en este caso específicamente en el cálculo numérico, entre otros).

b. Dificultad en la fluidez aritmética (comprensión de los números, ya sea en tareas sencillas o complejas, dificultad para contarlos, en el sentido numérico y al hacer cálculos aritméticos, entre otros).

c. Dificultad en el razonamiento matemático (dificultad para razonar los datos de un problema matemático sencillo o de mayor comple- 
jidad, entre otros aspectos que se vienen dando a través de un razonamiento lógico y lógico matemático).

d. Dificultad en la memorización de operaciones aritméticas (problemas para memorizar o retener información, así como ordenar mentalmente el proceso aritmético).

e. Dificultad para relacionar objetos (manejo y reconocimiento espacial).

Según Godino et al. (2003), la resolución de problemas es “esencial si queremos conseguir un aprendizaje significativo de las matemáticas. No debemos pensar en esta actividad sólo como un contenido más del currículo matemático, sino como uno de los vehículos principales del aprendizaje de las matemáticas” (p.66). Añadir la resolución de problemas en la enseñanza y el aprendizaje permite comprender aspectos teóricos a través de la practicidad. Según esta visión, es necesario provocar que niños, adolescentes, jóvenes y adultos encuentren un sentido matemático en sus actividades cotidianas, para desarrollar un pensamiento lógico matemático que permita posteriormente trabajar con facilidad un lenguaje matemático. Por ejemplo, en lugar de enseñar a sumar, restar, dividir o multiplicar a través de un ejercicio y utilizar un algoritmo para resolverlo, el trabajo de un profesor será instruir al estudiante — desde edades tempranas- para que pueda realizar operaciones aritméticas mentalmente, al contextualizar uno o varios problemas en sus actividades cotidianas, ejercitando con ello la memoria, el cálculo mental y el razonamiento desde su propia contexto y, paulatinamente, guiarlos para que puedan representarlo desde un lenguaje matemático, que les permita tener un conocimiento más profundo y desarrollar habilidades matemáticas, avanzando a su propio ritmo y con mayor interacción con su entorno. 
Respecto al diagnóstico de la discalculia, para su reconocimiento no solo deben predominar dichas dificultades sino ser persistentes, dificultando así el aprendizaje de las matemáticas, las cuales se van haciendo más complejas conforme se avanza en los grados escolares. Las dificultades estarán presentes tanto en procesos aritméticos como en el álgebra, en la resolución de problemas en contextos y, por ende, en el desarrollo del razonamiento lógico matemático, lo cual incidirá en otras áreas y causará una dificultad mayor por la falta de conocimientos básicos, los cuales ayudan a la creación de esquemas cognitivos y junto con la experiencia apoyan en la adquisición de nuevos conocimientos. En este sentido, es importante la colaboración de los profesionales de la educación con el neuropsicólogo y el psicopedagogo para una detección temprana y su reeducación. En consecuencia, las recomendaciones están encaminadas al cuidado de los tiempos en las sesiones de clases y los periodos atencionales que requieren las matemáticas específicamente.

En relación con los conceptos por naturaleza abstractos, que se pueden ver reflejados en la resolución de problemas, se sugiere la aplicación de ejercicios multisensoriales con predominio lúdico y aprendizajes significativos. Sin embargo, estos aspectos deben ser cuidadosamente respetados y aplicados en el trabajo en el aula, estableciendo redes de apoyo y colaboración dentro del grupo, de forma tal que la atención diferenciada no opaque en sí los principios de educación inclusiva, donde la cooperación es clave para el aprendizaje.

Asimismo, el tratamiento y la atención del aprendizaje de conceptos básicos en las matemáticas y las habilidades aritméticas — procesos afectados en los estudiantes con discalculia- encuentran un hito en la aplicación y el uso de las TIC para estimular procesos cognitivos. Por otro lado, Benedicto-López y Rodríguez-Cuadrado (2019) insisten en la planeación de la intervención de la mano del diseño curricular, con una 
marcada atención a las individualidades de cada estudiante, ello por la presencia de la dislexia y otros trastornos en los estudiantes discalcúlicos.

Respecto a la discalculia y las características que evidencian su presencia, se puede mencionar que hay una de ellas que impacta en las demás y si no es trabajada a tiempo se puede dar una afectación mayor al profundizar en contenidos matemáticos más complejos; es el sentido numérico, del cual Godino et al. (2009) refieren que está relacionado con la comprensión de los números que tienen las personas y su capacidad para resolver problemas. Por tanto, enseñar desde la práctica y estimular la enseñanza desde el saber hacer ayuda a crear estructuras mucho más sólidas desde el orden, el sentido y la presión que una o un estudiante con discalculia le da a ese pensamiento matemático para que, posteriormente, a través del lenguaje matemático, pueda ir construyendo el camino que lo llevará a la resolución y planteamiento de cada parte del proceso que desarrolló en la resolución de problemas. El proceso enseñanza-aprendizaje en un ambiente inclusivo obliga a que repensemos el proceso. Es ir de la competencia (componente práctico-saber hacer) del que aprende a la comprensión (componente teórico-saber qué y por qué) de lo que aprende.

\section{Dificultad específica en el aprendizaje de la lectoescritura. Dislexia}

La dislexia es un trastorno específico del aprendizaje, al igual que la discalculia. El DSM-5 en sus criterios diagnósticos aborda ambos trastornos bajo el mismo código con particularidades distintivas. Son varios los autores (García-Orza, 2012; Jacubovich, 2016) que coloquialmente le asignan la etiqueta diagnóstica de compañeros de viaje, aun cuando la dislexia por sí misma se caracteriza por la presencia de dificultades en áreas específicas de la lectura — precisión en la lectura de palabras, fluidez y comprensión de la lectura-, puede estar acompañada además de 
dificultades en la expresión escrita. En este apartado se hace alusión a la dislexia en el idioma español, siendo consecuente con la diferenciación entre el aprendizaje de la lengua española y el inglés, por citar un ejemplo. Al respecto, Jiménez (2014) y Rivadeneira-Ramos y Moya-Martínez (2021) hacen referencia comparativa en la dificultad en el aprendizaje de la lectura en niños ingleses respecto a niños que aprenden en lenguas distintas a esta, como resultado del proceso ortográfico en el idioma inglés.

En la búsqueda de un consenso en la definición y diagnóstico del trastorno, tema que remonta sus primeras contribuciones a los años sesenta de parte de las disciplinas neurológicas, varias investigaciones (Luque et al., 2016; Pascual \& Salas, 2021; Silva \& Capellini, 2019) hacen referencia a la dislexia como déficit fonológico, pero además correlacionan la causa de esta con una posible asociación con déficit cognitivos. Cueto et al. (2019) aseguran en su estudio que las dificultades respecto al procesamiento fonológico están relacionadas con la conciencia fonológica y la memoria verbal.

Por tanto, se asume que dicho trastorno se presenta con manifestaciones particulares en áreas específicas de la comprensión lectora que pueden o no abarcar la expresión escrita y el razonamiento matemático. Asimismo, se identifica dependiendo de la lengua materna y su aprendizaje con una marcada variabilidad al tratarse de relaciones fonemas-grafemas distintivas en cada caso. En este orden de ideas, es preciso mencionar los aspectos de tipo causal, los cuales no son reduccionista al déficit fonológico predictor en el trastorno, sino que se caracterizan por múltiples factores causales. Su origen neurobiológico, epigenético y ambiental hacen más compleja la determinación de una o varias causas como identitarias o definitorias para el diagnóstico de la dislexia. Sin embargo, su especificidad en las dificultades permite diferenciar entre otros trastornos donde se ven parámetros distintos en el desarrollo intelectual a pesar de la comorbilidad demostrada. 
Así como el diagnóstico y la evaluación deben llevarse a cabo desde la primera infancia, también es preciso atender el trastorno desde la inclusión y su tratamiento en contextos escolares. En consideración existen modelos de intervención neuropsicológica, logopédica, psicopedagógica y educativa que encuentran fundamento en el desarrollo de habilidades fonológicas y la practicidad de la lectura. Al respecto, Ripoll y Aguado (2016) promueven la aplicación de estas intervenciones en contextos escolares, asegurando su confiabilidad y resultados en poblaciones de niños, adolescentes y adultos disléxicos. Por tanto, la atención al tratamiento de la dislexia, por su carácter interdisciplinario, está estrechamente relacionado con los principios de la inclusión en la educación y, con ello, el desarrollo de propuestas educativas para cada estudiante en particular, pero diseñadas teniendo en consideración su aplicación en contextos reales de aprendizaje, diversos desde su concepción.

\section{Aportes de la neuroeducación a la atención de las dificultades de aprendizaje en prácticas educativas inclusivas}

Las neurociencias se caracterizan por una serie de disciplinas que comparten un fin común; no obstante, de esta han devenido otras que se especializan en determinadas áreas, con la intención de estudiar campos disciplinares específicos como las neurociencias cognitivas y la neuropsicología. Al respecto, la neuroeducación se reconoce como disciplina emergente de reciente aparición en materia neurocientífica y ciencias de la educación. Su nacimiento está asociado con la reconocida década del cerebro en los años noventa, en la cual surge una nueva línea de pensamiento, que tiene sus fundamentos en los aportes neurocientíficos a la educación, la pedagogía e incluso a la didáctica.

Desde su concepción, la neuroeducación intenta explicar el binomio cerebro-educación que tiene sus fundamentos en el funcionamiento cere- 
bral. Si bien, ha sido objeto de debate en investigaciones precedentes, no todo lo relacionado con la neurociencia es aplicable a la educación, así como tampoco pueden relacionarse todos los resultados de laboratorio con situaciones dinámicas y diversas que tienen lugar en contextos educativos. Los encuentros y desencuentros en la consolidación de la disciplina neuroeducativa se debaten en la comprensión de este principio.

En este sentido, los estudios en materia de neuroeducación intentan clarificar cuáles son los aportes de las neurociencias a la enseñanza y el aprendizaje, en la búsqueda de un consenso interdisciplinar donde se analicen con exhaustividad los contenidos. Lo que hoy las neurociencias conocen e investigan sobre las bases neurobiológicas del aprendizaje y la conducta, los procesos cognitivos y su relación con el rendimiento académico, los periodos sensitivos, las emociones y el aprendizaje se convierten en puntos de partida para la neuroeducación. Son evidencias teóricas y prácticas que se desarrollan en cerebros in vivo que pueden ser interpretados con la ayuda de las ciencias de la educación y sus prácticas dinámicas.

Por otra parte, los descubrimientos neurológicos que ayudan a explicar el funcionamiento cerebral, las características, las causas y las consecuencias de los daños cerebrales y déficits, pueden ayudar a la reeducación de las dificultades y trastornos en las distintas etapas de desarrollo que se presentan en las instituciones de educación. Sin embargo, la aportación puede darse de forma bilateral y recíproca, cuando el educador tiene la formación y la experiencia para poder complementar las investigaciones de laboratorio, como experto en las prácticas educativas.

Hace más de una década, Benarós et al. (2010) defendían el desarrollo de puentes interactivos entre la neurociencia y la educación; aseguraban que los profesionales de la educación tienen la responsabilidad con su práctica educativa de ser los principales exponentes y defensores 
de la neuroeducación. Hoy se habla del neuroeducador, como un nuevo profesional para los nuevos tiempos y preparado para aplicar el enfoque de enseñanza y educación basada en el cerebro (Mora, 2017).

La neuroeducación apuesta por un proceso de enseñanza-aprendizaje centrado en cómo aprende el cerebro y cómo se da el funcionamiento de los procesos cognitivos a nivel cerebral (Alargada \& Beut, 2019). Por su parte, Inostroza (2018) argumentó que los avances de las neurociencias han demostrado que "la comprensión de los procesos cognitivos; de las bases biológicas de la cognición; el lenguaje; del aprendizaje y memoria; y de las emociones o de las funciones ejecutivas; de un modo incuestionable se relacionan con los procesos educativos" (p.52). Por otro lado, la neuroeducación se interesa por comprender y analizar la educación inclusiva desde fundamentos neurobiológicos, por su predominio de bases neurológicas, genéticas en el déficit y trastornos que prevalecen en contextos educativos. Por tanto, se consideran aportes a la atención de las dificultades y trastornos de aprendizaje, en la medida que se cumple con la primera tesis que defiende la neuroeducación, la formación de profesionales de la educación bajo el enfoque cerebro-mente-educación para la posterior intervención en la enseñanza de los estudiantes que presentan estas necesidades y su inclusión social. Además, estos conocimientos permiten al docente contar con las herramientas para detectar a tiempo las dificultades y potencialidades de su grupo, reconocer cuando se está en presencia de un posible trastorno de aprendizaje o, por el contrario, ante un caso de abandono escolar, desinterés, desmotivación, aun cuando no sea el especialista que llevará a cabo el diagnóstico.

Los aportes neurocientíficos brindan conocimientos clave para la enseñanza, son teorías existentes con base científica, que no por compleja — como el cerebro en sí mismo- deja de ser relevante para la educación. Es una nueva mirada o, en palabras de Díaz y Chung (2020), un 
paradigma que puede enfrentar los desafíos en las aulas de América Latina. La responsabilidad está en el desarrollo de la ciencia y los avances tecnológicos como la principal fuente de conocimiento y, por ende, la aplicación de estos en escenarios diversos. La neuroeducación es otra perspectiva, otro sustento multidisciplinar; a los docentes es a quienes les corresponde profundizar en esta con pasos firmes para innovar en sus prácticas, pero sobre todo para estimular el desarrollo de una enseñanza inclusiva y aprendizajes significativos, con ritmos distintos y formas diversas (Díaz-Cabriales, 2021).

\section{Conclusiones}

La atención a las dificultades de aprendizaje comienza por la comprensión de las manifestaciones, las características diagnósticas y la comorbilidad con otros trastornos. Además, de la comprensión de las bases neurobiológicas, epigenéticas y ambientales, que provocan manifestaciones específicas en determinadas áreas y limitaciones causales. En este orden de ideas, se debe comprender mejor el trastorno para desarrollar tratamientos especializados o de orden multifactorial según sea el caso.

La prevalencia de las dificultades de aprendizaje en la educación se fundamenta en estudios precedentes, gracias a la educación inclusiva predominante en las instituciones. Sin embargo, para que se cumpla con los principios establecidos para la atención a la diversidad, es preciso mucho más que recibir estudiantes con distintas características en centros educativos. Los docentes deben ser agentes de cambio y facilitadores de aprendizajes. Sin embargo, ese es un proceso para el cual se deben preparar, porque las intervenciones pueden llegar a ser multimodales y requerir conocimientos, habilidades y actitudes para llevarlas a cabo junto con otros especialistas. 
La pedagogía inclusiva muestra los principales acercamientos a la atención de las necesidades en la escuela, su tratamiento dentro del grupo y el respeto a la individualidad y sus diversas expresiones. Por su parte, la neuroeducación, en sus aportes a la pedagogía y la didáctica, brinda contenidos neurocientíficos para la atención a dificultades específicas del aprendizaje como el trastorno del espectro autista (TEA) y el trastorno por déficit de atención e hiperactividad (TDAH). Sus premisas van dirigidas al aprendizaje basado en el conocimiento del cerebro y su funcionalidad, con la intención de promover espacios educativos congruentes con la interdisciplinariedad en la ciencia, capaces de entender y aplicar nuevas prácticas en función del proceso de enseñanza-aprendizaje. 
Capítulo 2

\section{Referencias}

Aguilera, A. (Coord.). (2004). Introducción a las dificultades de aprendizaje. McGraw-Hill.

Aguilera, A., \& García, I. (2004). El concepto de dificultades de aprendizaje. En A. Aguilera (Coord.), Introducción a las dificultades de aprendizaje (pp. 39-75). McGraw-Hill.

Alargada, D. R., \& Beut, J. A. G. (2019). Principios educativos y neuroeducación: una fundamentación desde la ciencia. Edetania: estudios y propuestas socio-educativas, (55), 155-180.

American Psychiatric Association (2014). Manual Diagnóstico y Estadístico de los Trastornos Mentales, (DSM-5) (5ºd). Editorial Médica Panamericana

Aránega, A. R. (2019). Dificultades Específicas del Aprendizaje. Psico/ Pedagógica, 11(14), 246-257.

Benarós, S., Lipina, S. J., Segretin, M. S., Hermida, M. J., \& Colombo, J. A. (2010). Neurociencia y educación: hacia la construcción de puentes interactivos. Revista de Neurología, 50(3), 179-186.

Benedicto-López, P., \& Rodríguez-Cuadrado, S. (2019). Discalculia: manifestaciones clínicas, evaluación y diagnóstico. Perspectivas actuales de intervención educativa. RELIEVE, 25(1), 1-11. http:// doi.org/10.7203/relieve.25.1.10125

Castro-Cañizares, D., Estévez-Pérez, N., \& Reigosa-Crespo, V. (2009). Teorías cognitivas contemporáneas sobre la discalculia del desarrollo. Revista de neurología, 49(3), 143-148. https://repositorio. uam.es/bitstream/handle/10486/672163/bases-carboni_rn_2006. pdf?sequence $=1 \&$ is Allowed $=\mathrm{y}$

Cueto, F., Soriano-Ferrer, M., \& Rello, L. (2019). Dislexia. Ni despiste ni pereza: Todas las claves para entender el trastorno. Madrid: La esfera de los libros. 
Díaz, M. R., \& Chung, C. K. K. (2020). Aportes de la Neurociencia a la Educación. Revista Científica en Ciencias Sociales, 2(1), 63-71.

Díaz-Cabriales, A. (2021). La neuroeducación en los programas de formación y profesionalización docente en México. Ciencia y Educación, 5(2), 63-78.

Estévez,N.,Reigosa,V.,\&Melie,L.2014).Basesbiológicasdelprocesamiento numérico: evidencias neuropsicológicas y anatómicas desde la discalculia del desarrollo (Tesis doctoral). Centro de Neurociencias de Cuba, La Habana.

Fernández, B. A. (2005). Detección, prevención y tratamiento de dificultades del aprendizaje. Ideaspropias Editorial.

Florian, L. (2015). Inclusive Pedagogy: A transformative approach to individual differences but can it help reduce educational inequalities? Scottish Educational Review, 47(1), 5-14.

Fourneret, P., \& Da Fonseca, D. (2019). Niños con dificultades de aprendizaje. Elsevier.

García-González, C., Herrera-Seda, C., \& Vanegas-Ortega, C. (2018). Competencias docentes para una pedagogía inclusiva. Consideraciones a partir de la experiencia con formadores de profesores chilenos. Revista latinoamericana de educación inclusiva, 12(2), 149-167.

García-Orza, J. (2012). Dislexia y discalculia. ¿Extraños compañeros de viaje? En Actas del XXVIII Congreso de AELFA (pp. 142-151). AELFA.

Geary, D. C. (2011). Consequences, characteristics, and causes of mathematical learning disabilities and persistent low achievement in mathematics. Journal of Developmental and Behavioral Pediatric, 32(3), 250-263. 
Godino, J. D., Batanero, C., \& Font, V. (2003). Fundamentos de la enseñanza y el aprendizaje de las matemáticas para maestros. Matemáticas y su didáctica para maestros. Universidad de Granada.

Godino, J. D., Font, V., Konic, P., \& Wilhelmi, M. (2009). El sentido numérico como articulación flexible de los significados parciales de los números. En J. M. Cardeñoso, \& M. Peñas (2009), Investigación en el aula de Matemáticas. Sentido Numérico (pp. 117-184). SAE Thales y Universidad de Granada.

Hammill, D. D. (1990). On Defining Learning Disabilities: An Emerging Consensus. Journal of Learning Disabilities, 23(2), 74-84. https:// doi.org/10.1177/002221949002300201

Inostroza, F. (2018). Neuroeducación social. Hacia una pedagogía emocionalmente inclusiva. Ril editores.

Jacubovich, S. (2016). Comorbilidad inversa entre discalculia y dislexia. VIII Congreso Internacional de Investigación y Práctica Profesional en Psicología XXIII Jornadas de Investigación XII Encuentro de Investigadores en Psicología del MERCOSUR. Facultad de Psicología, Universidad de Buenos Aires.

Jadue J., G. (2002). Factores psicológicos que predisponen al bajo rendimiento, al fracaso y a la deserción escolar. Estudios pedagógicos (Valdivia), (28), 193-204. https://doi.org/10.4067/ S0718-07052002000100012

Jimenez, J. E. (2014). Dislexia en español. Madrid: Ediciones Pirámide. Keeler M. L., \& Swanson, H. L. (2001). Does strategy knowledge influence working memory in children with mathematical disabilities? Journal of Learning Disabilities, 34, 418-434.

Klinger, C. L., Mejía, C. M., \& Posada, L. M., (2011). La inclusión educativa: un escenario de expresiones afectivas como mediadoras del aprendizaje. Plumilla educativa, 8(2), 176-190. 
López, M. M. (2017). La formación de los profesores y las dificultades de aprendizaje. Revista de Educación Inclusiva, 7(2), 98-100.

Luque, J. L., Giménez, A., Bordoy, S., \& Sánchez, A. (2016). De la teoría fonológica a la identificación temprana de las dificultades específicas de aprendizaje de la lectura. Revista de logopedia, foniatría y audiología, 36(3), 142-149.

Maldonado, J. O. (2021). Neuroropsicología infantil y comorbilidad en los trastornos del neurodesarrollo. Teoría y Práctica: Revista Peruana de Psicología CPSP-CDR-I, 3(1), e41. http://revistateoriaypractica. com/index.php/rtyp/article/view/41

Mejía, C., \& Cifuentes, V. V. (2015). Comorbilidad de los trastornos de lectura y escritura en niños diagnosticados con TDAH. Psicología desde el Caribe, 32(1), 121-143.

Mora, F. (2017). Neuroeducación. Solo se puede aprender lo que se ama. Alianza Editorial.

National Joint Committee on Learning Disabilities. (1990). Definition of Learning Disabilities. https://njcld.files.wordpress.com/2018/10/ ld-definition.pdf

Moyano, M., Ramírez, A., Martos, M. D., \& Anguita, V. (2017). El absentismo escolar en Andalucía (España): balance y propuestas de futuro en el marco de la Unión Europea. Opción: Revista de Ciencias Humanas y Sociales, (84), 65-90.

Pascual, M., \& Salas, N. (2021). The cognitive profile and text-based traits of struggling writers. Journal for the Study of Education and Development, 44(1), 219-253.

Ríos, J. A., \& Lopez, C. R. (2017). Neurobiología de los trastornos del aprendizaje y sus implicaciones en el desarrollo infantil: propuesta de una nueva perspectiva conceptual. Psicoespacios: Revista virtual de la Institución Universitaria de Envigado, 11(19), 174-192. 
Ripoll, J. C., \& Aguado, G. (2016). Eficacia de las intervenciones para el tratamiento de la dislexia: una revisión. Revista de Logopedia, Foniatría y Audiología, 36(2), https://doi.org/10.1016/j. rlfa.2015.11.001

Rivadeneira-Ramos, G. A., \& Moya-Martínez, M. E. (2021). La dislexia y su incidencia en el aprendizaje del idioma inglés. Polo del Conocimiento, 6(2), 64-82.

Romero, J. F. \& Lavigne, R. (2005). Dificultades en el aprendizaje: Unificación de criterios diagnósticos. Junta de Andalucía. https:// www.uma.es/media/files/LIBRO_I.pdf

Rosselli, M., \& Matute, E. (2011). La Neuropsicología del Desarrollo Típico y Atípico de las Habilidades Numéricas. Revista de Neuropsicología, Neuropsiquiatría y Neurociencia, 11(1), 123-140. https://dialnet. unirioja.es/servlet/articulo?codigo $=3640864$

Ruíz, P. J. (2013). Problemas escolares en adolescentes. Pediatría integral, 17(2), 117-127. https://www.pediatriaintegral.es/numerosanteriores/publicacion-2013-03/los-problemas-escolares-en-laadolescencia/

Scrich, A. J., Cruz, L. D., Bembibre, D. B., \& Torres, I. (2017). La dislexia, la disgrafía y la discalculia: sus consecuencias en la educación ecuatoriana. Revista Archivo Médico de Camagüey, 21(1), 766-772.

Silva, C., \& Capellini, S. A. (2019). Indicadores cognitivo-linguístico em escolares com transtorno fonológico de risco para a dislexia. Distúrbios da Comunicação, 31(3), 428-436.

Torresi, S. (2020). Acerca de números, dificultades e intervenciones. Journal of Neuroeducation, 1(1), 136-140.

Vallejo, M. (2010). Dificultades de aprendizaje. Revista digital de innovación y experiencias educativas, 25, 1-10. 


\section{Capítulo 3}

\section{Estrategias didácticas para docentes en la enseñanza del derecho}

Ariana Alejandra Atilano Bravo y Julieta López Zamora

La didáctica es una forma de lograr la participación del estudiante en su proceso de formación, de una manera autónoma, reflexiva y consciente, pero orientada desde mecanismos que permitan colocar en escena sus lecturas del mundo y de los autores pertinentes a su perfil profesional (Muñoz et al., 2011). Se entiende como un procedimiento y, por consiguiente, una actividad socio afectiva por la que se relacionan los medios con los fines y, de esta manera, se logra que los procesos de enseñanza y aprendizaje sean efectivos y eficaces, beneficiando al estudiante, proporcionando habilidades y conocimientos útiles transferibles a situaciones dentro y fuera del contexto escolar (Feo, 2008). De acuerdo con Goodlad (1995), la formación universitaria tiene que ser una formación que enriquezca a los sujetos en todos los ámbitos de su desarrollo: personal, social, intelectual y práctico.

En este sentido, según Campari (2005), el profesor se preocupa casi de forma exclusiva de organizar los materiales de acuerdo con la lógica de la disciplina y de presentarlos por medio de una exposición, predominantemente abstracta, de datos, métodos y conceptos, y de la lectura parafraseada de libros de texto y apuntes. Opuesto a esto, preparar la di- 
dáctica requiere de un trabajo minucioso para facilitar los aprendizajes de los estudiantes y de una estrategia sólida que integre actividades para propiciar la interacción de los alumnos con determinados contenidos.

Lo anterior requiere un esfuerzo físico y mental del profesor para cumplir con sus funciones pedagógicas implícitas en el proceso de enseñanza-aprendizaje, una de las piezas fundamentales de los procesos, puesto que de ella dependen la orientación y la operatividad; además, im-

plica una interrelación constante con los demás elementos del diseño de enseñanza, como los objetivos o competencias a desarrollar, los contenidos, las características, las conductas, las habilidades de los estudiantes, los medios instruccionales y la evaluación (Gutiérrez \& García, 2016).

\section{Estrategias didácticas}

Las estrategias didácticas constituyen una herramienta esencial para generar un aprendizaje eficaz; la selección y aplicación de dichas estrategias implica considerar el contexto de la enseñanza y el aprendizaje para apoyar en la construcción del conocimiento de los estudiantes. De acuerdo con la Organización de las Naciones Unidas para la Educación, la Ciencia y la Cultura (UNESCO, 2008), las estrategias didácticas combinan y organizan un conjunto de métodos y materiales escogidos para alcanzar logros académicos, con la finalidad de desarrollar en los estudiantes un aprendizaje significativo. Así, las estrategias son los medios y los recursos que se ajustan para lograr aprendizajes a partir de la intencionalidad del proceso educativo (Díaz Barriga \& Rojas, 1998), planteando una educación activa y una perspectiva diferente acerca de pensar y realizar la docencia, que ya no se limita solo a procurar la existencia de la comunicación e interacción grupal, sino que trabaja en los contextos para promover y aprovechar intencionadamente la interacción como fuente y medio de experiencias de aprendizaje (Muñoz et al., 2011). 
Para trabajar en el diseño de estrategias didácticas se debe considerar el fomento de aprendizajes significativos y estratégicos, que los momentos y eventos que la integren se relacionen de manera lógica con las características de la audiencia y del espacio y, a su vez, con los métodos, técnicas y actividades en función de los objetivos a alcanzar, que promuevan en el estudiante espacios para aprender a aprender (Feo, 2008). Por lo tanto, son procedimientos (métodos, técnicas, actividades), por medio de los cuales el docente y los estudiantes organizan las acciones de manera consciente para construir y lograr metas previstas e imprevistas en el proceso de enseñanza y aprendizaje, adaptándose a las necesidades de los participantes de manera significativa (Feo, 2010).

En este tenor, Mansilla y Beltrán (2013) mencionan que "La estrategia didáctica con la que el profesor pretende facilitar los aprendizajes de los estudiantes está integrada por una serie de actividades que contemplan la interacción de los alumnos con determinados contenidos” (p.29). Así, las estrategias didácticas son el conjunto de procedimientos, apoyados en técnicas de enseñanza, que tienen por objeto llevar a buen término la acción didáctica, es decir, alcanzar los objetivos de aprendizaje (Rivero et al., 2013). Además, son construcciones lógicas pensadas para orientar el aprendizaje y la enseñanza de las competencias en los diversos niveles educativos, a través de procedimientos compuestos de un conjunto de etapas que pretenden facilitarles el aprendizaje de estas a los estudiantes (García, 2010).

Alcanzar los objetivos de aprendizaje es el ideal del docente y para acercarse a ellos requiere diseñar los procedimientos, apoyados en técnicas de enseñanza que lleven a buen término la acción didáctica. Por lo tanto, pensar en prácticas pedagógicas en la universidad implica diseñar estrategias didácticas orientadas a que los educandos no solo reciban información, sino que sean capaces de modificarla y aplicarla, de compar- 
tir las inquietudes actuales en torno al conocimiento, de problematizar, descomponerlo y recomponerlo en su comprensión personal (Badilla et al., 2014).

En este aspecto, la didáctica crítica puede ser de utilidad, ya que es el método hermenéutico que utiliza la interpretación como forma de aprehensión de la totalidad en lo particular y permite desarrollar competencias comunicativas, propositivas, argumentativas e interpretativas tan esenciales para el estudiante (Andrade \& Muñoz, 2012) y "orienta la acción formativa, en un contexto de enseñanza-aprendizaje, mediante procesos tendencialmente simétricos de comunicación social" (Rojas, 2009, p.95) que incentiva:

la participación del estudiante en su proceso de formación, de una manera autónoma, reflexiva y consciente, pero a la vez orientada desde mecanismos que permitan colocar en escena sus lecturas del mundo y de los autores pertinentes a su perfil profesional. (Muñoz et al., 2011, pp.31-32).

Esta es, por tanto, una perspectiva diferente de pensar y realizar la docencia, que ya no se limita sólo a procurar la existencia de la comunicación e interacción grupal, sino que trabaja en los contextos para promover y aprovechar intencionadamente la interacción como fuente y medio de experiencias de aprendizaje.

La didáctica crítica plantea una alternativa educativa activa, formadora, incluso interdisciplinaria, por la cual el estudiante aprende a aprender, aprende a ser y adquiere habilidades para leer, interpretar, sistematizar, elaborar y aplicar el conoci- 
miento no sólo en el aspecto estrictamente académico, sino en todo momento importante de su vida, aspecto fundamental del aprendizaje. (Muñoz et al., 2011, p.36)

Por lo tanto, se puede decir que la estrategia didáctica es una secuencia de acciones donde se buscar generar aprendizaje significativo en los estudiantes de manera flexible y adaptable para promover el aprender a aprender. El educando no solo es un receptor, será capaz de aplicar, compartir y modificar conocimiento, así como de problematizar, descomponer y recomponer una situación real por medio de su comprensión personal. Por su parte, la didáctica crítica se puede definir como el desarrollo de competencias tanto comunicativas, propositivas, argumentativas e interpretativas, para lograr la participación del estudiante de manera autónoma, reflexiva y consciente con la intensión de que pueda aplicar sus conocimientos en situaciones reales.

\section{Universidad Autónoma de Baja California (UABC)}

El modelo educativo de la UABC (2018) tiene su sustento filosófico y pedagógico en "el constructivismo, que promueve un aprendizaje activo y centrado en el alumno [...] que enfoca su atención en los aprendizajes, en vez de limitarse a la transmisión de conocimiento” (p. 33). Su modelo es flexible, con un enfoque por competencias, para aprender a aprender y hacerlo de manera autónoma, significativa y cooperativa, tal como lo señala Romero (2009 como se citó en Hernández et al., 2015); de tal manera que, la formación de los alumnos asegure un perfil de egreso adecuado para integrarse productivamente a la sociedad dentro de un área profesional.

Para que este modelo opere de manera adecuada y cumpla con sus objetivos, se requiere de "la participación de todos los [...] involucrados en 


\section{Figura 1}

\section{Ruta metodológica}

\section{TIPO}

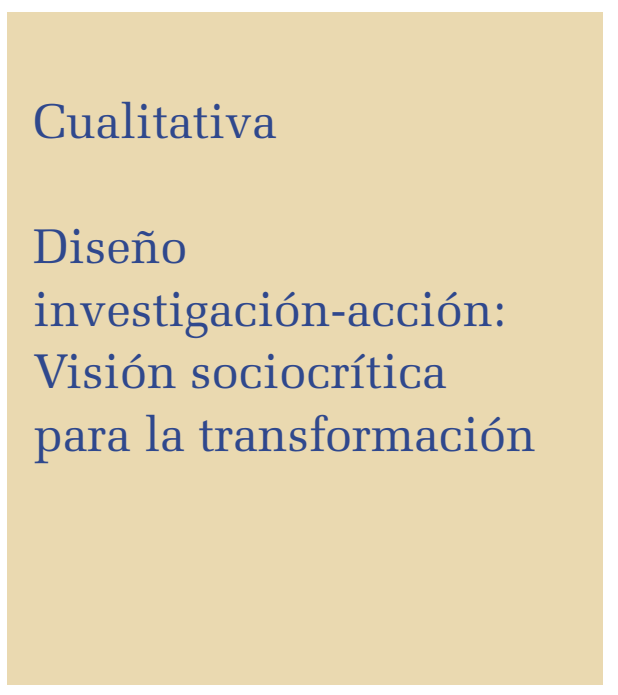

TÉCNICAS

- Dos entrevistas semiestructuradas a PTC

- Veinte encuestas a docentes de derecho (asignatura y tiempo completo)

- Observación no participante en una clase de Derecho.

\section{CATEGORÍAS}

1. La didáctica crítica y el trabajo docente

2. La enseñanza del Derecho y su relación con el Modelo Educativo de la $U A B C$

3. Trascendencia de la formación pedagógica del docente

1. Se realizó observación dentro del aula, días preestablecidos por el docente que impartía la asignatura.

2. Las entrevistas, grabadas y transcritas.

3. Las encuestas se aplicaron por medio de correo electrónico. La información se organizó de acuerdo con dos categorías para el análisis.

el proceso de aprendizaje de los alumnos, pues se requiere su compromiso de conocer, comprender y llevar a la práctica [dicho modelo]" (UABC, 2018, p.11).

\section{Facultad de Derecho-Mexicali}

La Facultad de Derecho-Mexicali (FDM) de la UABC tiene como misión "preparar profesionales del Derecho con una formación integral y de calidad, capaces de responder con alto sentido propositivo a los problemas jurídicos, con amplio conocimiento en el área, dotados de habilidades, actitudes y aptitudes” (UABC, s.f.). Dentro de su oferta académica, se encuentran los siguientes programas: Licenciatura en Derecho, Especiali- 
dad en Derecho, Maestría en Ciencias Jurídicas, Doctorado en Derecho y Doctorado en Ciencias Jurídicas. Aporta una importante actuación, ya que cuenta con un bufete jurídico gratuito, el cual proporciona servicio de calidad a la comunidad en general, brindando atención principalmente a la población de escasos recursos.

Actualmente, cuenta con una matrícula de Licenciatura de 2007 alumnos y con la siguiente planta docente: 178 profesores, de los cuales 25 son Profesores de Tiempo Completo (РтC), dos Profesores de Medio Tiempo (Рмт) у cuatro Técnicos Académicos (тА). De los 146 profesores de asignatura, 17 laboran en los poderes judiciales estatal y federal, mientras que el resto se dedica a su práctica profesional (UABC, 2019).

Los docentes de la Facultad de Derecho se caracterizan por impartir sus asignaturas partiendo de la experiencia en el campo laboral y por desarrollar su formación pedagógica en su paso por la vida universitaria. Debido a esto, surge el interés de contribuir a la mejora académica, brindando un panorama amplio a los docentes respecto a las estrategias didácticas, con el fin de ayudar en el fomento del aprendizaje significativo y la formación integral en los estudiantes universitarios.

Al respecto, se realizó una investigación que tuvo como objetivo desarrollar y proponer un manual con estrategias didácticas para docentes de la enseñanza del Derecho, con la finalidad de mejorar el rendimiento académico, considerando el modelo educativo de la UABC.

Para lograrlo, primero se exploraron las estrategias didácticas que implementan los docentes en el aula para la enseñanza del Derecho, así como el apego al modelo educativo de la UABC, con el fin de tener un diagnóstico sólido que permitiera diseñar el manual, integrando la didáctica crítica. En este capítulo, se presentan los resultados de esta fase diagnóstica. 
Capítulo 3

\section{Método}

La fase diagnóstica de la investigación se realizó de agosto de 2019 a mayo de 2020 en la Facultad de Derecho de la UABC, campus Mexicali, con el objetivo de dar a conocer las formas de trabajo en el aula de los docentes de derecho respecto a la didáctica. La investigación fue de tipo cualitativa, apoyada con el método de investigación-acción —a través de las técnicas de la observación no participante, encuesta y entrevista estructurada (figura 1)—, con la intención de intervenir en las situaciones para mejorar la acción, debido a que son los profesores los que conocen los verdaderos problemas y la investigación científica no parece haberles dado una solución.

La investigación-acción contempla al profesor como investigador, asumiendo este la responsabilidad de estudiar su propia actividad educativa con la intención de mejorarla, debido a que las reformas educativas son impuestas desde arriba y no producen innovación, si antes no se ha conseguido cambiar la mentalidad del profesor y sus actitudes (Bausela, 2004; Munarriz, s.f.).

Los profesores, en su acción diaria, realizan prácticamente este mismo proceso, sin embargo, como indican Kemrnis y McTaggart (1988), "la investigación/acción significa planificar, actuar, observar y reflexionar más cuidadosamente, más sistemáticamente y más rigurosamente de lo que suele hacerse en la vida cotidiana” (p.16). Por lo tanto, se considera el método más apropiado para trabajar en el proyecto para tener el contacto con los docentes y dialogar sobre los procesos, que puedan brindar sugerencias y aportaciones de acuerdo con el lugar que ocupan en la institución, pero sobre todo en el aprendizaje de los estudiantes. El proceso permite realizar un diagnóstico a partir de la escucha activa para hacer una propuesta de intervención partiendo de sus necesidades reales y teniendo la certeza de que será una propuesta aprovechada por 
los docentes de Derecho y puedan brindar una educación de calidad a los estudiantes universitarios.

\section{Participantes}

Se trabajó con docentes que imparten asignaturas como: Lógica, Teoría del estado, Derecho de las personas, familias y bienes, Derechos reales y sucesiones; en la etapa básica que marca el mapa curricular 2015-2 dentro de la licenciatura. Se seleccionaron a dos docentes de Tiempo Completo (тс) para las entrevistas semiestructuradas, se aplicaron 15 encuestas de manera virtual a docentes de tiempo completo y asignatura y se realizó observación dentro del aula durante una clase impartida por un docente.

\section{Procedimiento}

1. Se realizó observación dentro del aula, días preestablecidos por el docente que impartía la asignatura.

2. Las entrevistas, fueron grabadas y transcritas, con consentimiento previo de los docentes.

3. Las encuestas se aplicaron por medio de correo electrónico.

4. La información se organizó de acuerdo con dos categorías para el análisis: (a) estrategias didácticas y (b) didáctica crítica.

\section{Resultados}

A continuación, se presentan los resultados obtenidos a través de los instrumentos aplicados a docentes de la Facultad de Derecho, campus Mexicali, con respecto a las estrategias didácticas que usan dentro del aula actualmente. Asimismo, se mencionan aspectos relevantes que se obtuvieron de acuerdo con las categorías establecidas. 
Capítulo 3

\section{Didáctica crítica y trabajo docente}

Una de las preguntas realizadas durante la entrevista fue en referencia al concepto que se tiene de la palabra enseñar. Al respecto, un participante indicó que es transmitir un conocimiento, pero considerando lo siguiente:

Como en toda comunicación es importante que el mensaje por el emisor este correctamente lazando, que el canal sea el correcto y el adecuado y que luego el receptor pues también por su parte este preparado, atento, estemos en la misma frecuencia solamente así te aseguras que el mensaje llega correctamente y queverdaderamentehastransmitidounconocimiento.(Sujeto2)

En el mismo sentido, otro participante contestó lo siguiente:

Bueno para mi enseñar, obviamente considero que es un arte por parte de las personas y es transmitir los conocimientos para que a su vez estos puedan ser replicados y a su vez puedan ser expuestos en determinadas áreas de la profesión. (Sujeto 3)

Respecto al concepto de aprendizaje, un participante compartió que ha de considerar un lazo con el concepto de enseñar, pues al enseñar se está generando un aprender. Así lo indicó: “La parte de enseñar correspondería al emisor transmisor de este conocimiento el aprendizaje sería el receptor, es decir recibir conocimientos y hacerlos tuyos" (Sujeto 2). Mientras que, otro participante consideró "Que es la meta de toda enseñanza cuando un alumno ya aprendido lo que tú le has dado en una clase considero que ya estamos del otro lado del camino” (Sujeto 3). 
En la encuesta realizada, se preguntó sobre el papel que juegan los criterios de evaluación en la efectividad del aprendizaje de los estudiantes, al respecto se menciona que son un 50\% confiables los resultados obtenidos; cuatro docentes comparten que esto ayuda a que el estudiante sea responsable y comprometido con sus resultados después de una evaluación; mientras que 14 docentes consideran que el tener criterios preestablecidos es la pauta para la expectativa a lograr, ya que les permite cuantificar el trabajo en la asignatura. Finalmente, un docente mencionó que para él no son resultados confiables y que toma en mayor consideración las evaluaciones diagnósticas.

\section{La didáctica de la enseñanza}

De acuerdo con las observaciones realizadas dentro del aula, se encontró lo siguiente: se observó que el Sujeto 1, al llegar al aula ya tenía preparado el contenido que se abordó durante esa sesión, lo cual permitió entrar rápidamente a la revisión de contenido; la mayor parte del tiempo el docente tuvo la palabra, pero hubo pequeños intervalos donde los estudiantes comentaban sus puntos de vista y las dudas que habían surgido sobre el tema.

En la misma línea, un participante mencionó durante la entrevista que la didáctica de sus clases depende del contenido que se aborda, ya que hay algunas que pueden ser dinámicas, pero otras son de mucha teoría.

Derecho, si bien es cierto que no es una disciplina digamos para estudiar que no se pueda escapar mucho de lo teórico, o sea, se pueden ver en casos concretos, en casos reales todo lo que has visto en la teoría y bien es cierto que mis asignaturas sobre todo Filosofía, Teoría, Lógica son asignaturas muy abstractas, muy etéreas, complicado de plasmarlo en lo práctico. (Sujeto 2) 
Por otra parte, otro participante comentó que desarrolla sus clases mediante casos prácticos, que van siempre de la mano de la teoría necesaria. Es un estilo de manual lo que ella resguarda y que lo aplica cada semestre, solo lo va adecuando al contenido que irá revisando con los estudiantes.

Se desarrollan las habilidades con las que quiero que el alumno cuente; como son la argumentación, la oralidad, como el análisis de los problemas, obviamente solucionar problemas puesto que la carrera de nosotros tiene gran relevancia en cuanto a lo que es el solucionar un problema. (Sujeto 3)

Para complementar la información, a través de la encuesta se indagó en el método de enseñanza que desarrollan en sus clases: 12 docentes mencionaron que es de manera colaborativa, ya que les permiten a los estudiantes participar activamente en el proceso de aprendizaje, aportando sus puntos de vista en cuanto a los temas que se abordan. Cuatro docentes comentan que consideran promover el trabajo colaborativo, la divulgación y la comunicación en el aula. Tres docentes comentaron que la manera de llevar a cabo su clase es por medio de la divulgación, es decir, se permite al profesor exponer a los estudiantes el contenido de la materia. Un docente compartió que la manera en la que se desarrolla su clase es por medio de equipar a sus estudiantes con un método de investigación y, a partir de esto, construir nuevos significados y conocimientos.

Respecto a la planeación de clases, 17 docentes mencionaron que cumplen con el objetivo de formar estudiantes capaces, proactivos, críticos y con pensamiento autónomo. Dos docentes se mostraron neutrales ante esta pregunta. Y un docente mencionó que no considera que sus planeaciones cumplan con los principios orientadores. 
Partiendo de la apreciación que poseen en cuanto al concepto de enseñar, los docentes en la entrevista comentaron que es importante mantener una comunicación adecuada con los estudiantes para tener su atención y lograr la transmisión de conocimiento, sin dejar de lado la preparación del que enseña. Perciben la enseñanza como un arte, ya que conforme pasan generaciones por las aulas, los conocimientos pueden ser replicados. Indicaron que el aprendizaje está muy ligado y este se va a dar una vez que se ha recibido correctamente. Asimismo, indicaron que el establecer criterios de evaluación para las diferentes asignaturas invita al estudiante a ser responsable y comprometido con su aprendizaje; les genera una expectativa de lo que se requerirá para acreditar el curso y poseen un $50 \%$ de confiabilidad en cuanto al aprendizaje obtenido.

Realizando observación en cuanto a la didáctica que se implementa dentro de las aulas, se percibió una previa preparación tanto del grupo como del docente para aprovechar los 50 minutos de clase que se tenían. Los docentes entrevistados mencionaron una didáctica similar y agregaron que algunas materias son flexibles, en el sentido de buscar lo práctico, pero otras definitivamente son solo teóricas y se les dificulta modificar la manera de llevar la clase.

A su vez, comentaron acerca de un manual de casos prácticos que cada semestre se ajusta de acuerdo con las necesidades del grupo. Al preguntar sobre el método de enseñanza que predomina en sus clases, la mayoría mencionó el trabajo colaborativo, ya que este permite a los estudiantes participar activamente en su proceso de aprendizaje; otros más agregaron el método de divulgación, ya que permite al docente exponer el contenido; finalmente, mencionaron el método de investigación, pues lo consideran apropiado para la construcción de nuevos significados. En cuanto a las planeaciones de clase, los docentes coincidieron en que cumplen con el objetivo de proactividad, pensamiento autónomo y el fortalecimiento del pensamiento crítico en sus estudiantes. 
Capítulo 3

\section{Estrategias para enseñar la disciplina del Derecho}

Las estrategias observadas en el Sujeto 1 dentro del aula fueron la exposición, la retroalimentación de información y las aportaciones que los alumnos consideraron relevantes, para finalmente hacer espacio para preguntas-respuestas.

Con respecto a lo anterior, un participante comentó que tiene varias estrategias a aplicar en cada materia, de acuerdo como se necesita trabajar con los grupos. A continuación, comparte algunas:

Les elaboro a los muchachos, a los alumnos lo más importante, lo más relevante de cada uno de los manuales, he creado unos apuntes con eso, entonces cada tema se lo subo a Facebook y entonces tenemos un grupo ahí y ellos lo descargan y le digo para el próximo día lo traigan por favor aprendido entonces, aprendido no, perdón, lo traigan impreso y en la clase leemos el tema y conforme leemos el tema que nos sirve como guion; voy explicando y desarrollando cada uno de los puntos fundamentales.

También traslado muchas veces la responsabilidad a ellos con la elaboración de trabajos y exposiciones. (Sujeto 2)

Asimismo, otro participante señaló que la doctrina que ha implementado desde hace varios años le ha llevado a desarrollar lo que el Modelo Educativo ha establecido tanto para el estudiante como para el docente, pues:

Tienen que leer previamente, así como los artículos aplicables al caso, entonces ellos únicamente lo que hacen es leer la doctrina, analizar los artículos y solucionar el caso práctico 
que yo les pongo, con eso lo hacen en clase; con argumentos, mediante razonamientos y pues también aquí algo muy interesante a esta metodología que yo adopte es precisamente ver que un problema tiene varias soluciones no nada más una. (Sujeto 3)

Para complementar, la encuesta permitió obtener las siguientes estrategias que implementan los docentes dentro del aula: el método de casos, las experiencias de la vida diaria, la ludificación, la interacción con el grupo por medio de preguntas y respuestas generando una retroalimentación constante, el trabajo en equipos, la participación por parte de los estudiantes, la lluvia de ideas, las exposiciones, los mapas mentales, los mapas conceptuales, el método mayéutica, la generación de debates, la investigación de los temas que se abordarán, la realización de ejercicios prácticos, el examen, el análisis y la reflexión del contenido.

Es necesario precisar que un docente permaneció neutro ante la pregunta de la implementación de estrategias didácticas para obtener mayor aprovechamiento en el aprendizaje de los estudiantes; uno más estuvo en desacuerdo ante esto y el resto estuvo de acuerdo en que son un beneficio para sus estudiantes.

\section{Discusión}

Se encontró que el docente de Derecho, para impartir su materia, parte de la experiencia en su campo laboral y aplica estrategias que aplicaban sus profesores en el aula en su paso por la vida universitaria. Por lo tanto, la mayoría de las clases se centran en memorizar el texto y repetir lo que el profesor expone; de tal forma que se limitan a la transmisión de la información sin retroalimentación, juicios y críticas constructivas. 
De manera general, los docentes indicaron que el contenido a trabajar se entrega días previos a la clase y es responsabilidad del estudiante realizar un análisis y reflexión para tener mayor conocimiento y poder participar; por otra parte, comentaron que en algunas sesiones la estrategia es que los estudiantes expongan el tema al resto del grupo.

La mayoría de los docentes consideran benéfico implementar estrategias didácticas en sus diferentes asignaturas y reflexionan sobre la importancia de qué hacer con ellas, cómo se hará la interacción y cómo variar las maneras de trabajar para enriquecer el proceso de aprendizaje, tal como lo señala Villarreal-Treviño (2006). Aunque es importante mencionar que hubo docentes que no contemplan la implementación de estrategias en su planeación de clase, pues no le ven un beneficio.

Los entrevistados mencionaron que el desenvolvimiento de algunos docentes se va generando conforme la experiencia y a través de cursos de didáctica para el control de grupo; agregan que hay quienes se desencuelven fácilmente y otros tantos que deben trabajar un poco más en ese aspecto. Comparten que al iniciar este camino de la docencia no es tan sencillo para todos, pues desconocen cómo actuar en ciertas situaciones, pero la experiencia ha ido brindando esas respuestas; sobre todo en el aula, pero también intercambiar experiencias con compañeros es de gran ayuda.

Asimismo, se pudo observar el dominio del contenido que tiene el docente en cuanto a la asignatura que imparte y lo fluida que se vuelve la sesión si tienen conocimiento teórico respecto a lo que se enseña al grupo. Sin embargo, comentan que no es suficiente, ya que hacen alusión a la necesidad de saber manejar al grupo y contar con una experiencia docente básica, ya que pueden ser expertos en el tema, pero no lograr una enseñanza-aprendizaje efectiva. Tal como lo mencionan Merellano-Navarro et al. (2016), quienes concuerdan con que el buen docente univer- 
sitario necesita poseer características que transiten entre las habilidades pedagógicas, enfatizando en todo momento su accionar en el aprendizaje.

Siguiendo esta idea, los docentes consideran que su unidad académica se distingue por brindar una educación de calidad, ya que se tiene el dominio del tema y saben enseñar. Al respecto, según Bocanegra (2012), no se trata de convertir abogados en educadores sino trabajar a partir de los conocimientos de otras disciplinas en la medida que sean relevantes para el desempeño en las tareas jurídicas.

Respecto al rol del docente, se observó que funge como facilitador del aprendizaje de sus estudiantes, pues les comparte información y les solicita que se apoyen de otros autores de la disciplina para enriquecer lo revisado en la sesión de clase. Sin embargo, también consideran que el desenvolvimiento de algunos docentes se va generando conforme a la experiencia y la formación a través de cursos de didáctica en cuanto al control de grupo; agregan que hay a quienes se les da sin mucho esfuerzo y otros tantos deben trabajar un poco más en ese aspecto.

Los docentes compartieron que algunos trabajan bajo un manual elaborado hace algún tiempo, el cual ha generado cierta resistencia por parte de los estudiantes, ya que este los lleva a ser más críticos y a responsabilizarse de su aprendizaje; al respecto, según García (2006), el alumno universitario se caracteriza por un perfil de estudiante determinado, que es preciso conocer para que el cambio anunciado tenga un desarrollo exitoso y se consigan los resultados esperados. Ante lo cual, es necesario no perder de vista que el alumno persigue diferentes metas a lo largo del proceso enseñanza-aprendizaje, con las que pretende lograr el éxito de la realización de las actividades académicas, de acuerdo con Alonso (2001). 
Capítulo 3

\section{Referencias}

Alonso, J. (2001). Motivación y estrategias de aprendizaje. Didáctica universitaria. Muralla.

Andrade, M. C., \& Muñoz, C. (2012). La didáctica crítica: una opción pedagógica para la universidad de hoy. Revista de investigaciones UNAD, 11(2). https://doi.org/10.22490/25391887.790

Badilla I., Ramírez, A., Rizo, L., \& Rojas, K. (2014). Estrategias didácticas para promover la autorreflexión de la praxis en los procesos de formación docente. Revista Electrónica Educare, 18(2), 213. https:// doi.org/10.15359/ree.18-2.11

Bausela, E. (2004). La docencia a través de la investigación-acción. Revista Iberoamericana de Educación, 35(1). https://rieoei.org/RIE/ article/view/2871/3815

Bocanegra, H. (2012). La Enseñanza del Derecho y la formación de los abogados. Revista Republicana, (12). http://ojs.urepublicana.edu. co/index.php/revistarepublicana/article/view/50

Campari, S. (2005). Enseñar Derecho pensando en el profesional del siglo XXI. Academia. Revista sobre la enseñanza del Derecho, 3(5), 189.

Díaz Barriga, F., \& Rojas, G. (1998). Estrategias docentes para un aprendizaje significativo: una interpretación constructivista. McGraw-Hill.

Feo, R. (2008). Consideraciones básicas referentes a las estrategias didácticas para la construcción de una práctica docente estratégica. http://files.estrategias2010.webnode.es/200000047cd195ce135/1.\%20Estrategias\%20did.pdf

Feo, R. (2010). Orientaciones básicas para el diseño de estrategias didácticas. Tendencias Pedagógicas, 16, 221-236. https://revistas. uam.es/tendenciaspedagogicas/article/view/1951 
García, J. A. (2010). Algunas estrategias didácticas para la formación por competencias: el aprendizaje basado en problemas (ABP) y el portafolio del alumno. Revista Electrónica de Desarrollo de Competencias (REDEC), 1(5), 123-147. http://dta.utalca.cl/ojs2/ index.php/fcompetencias/article/view/71/67

García, M. R. (2006). Las competencias de los alumnos universitarios. Revista Interuniversitaria de Formación del profesorado, 20(3), 253-269.

Goodlad, J. I. (1995). Ralph Tyler: The educator's educator. Educational Policy, 9(1), 75-81. https://doi.org/10.1177/0895904895009001004

Gutiérrez, M., \& García, J. L. (2016). Estilos de aprendizaje y diseño de estrategias didácticas desde la perspectiva emocional del alumnado y del profesorado. Revista de Estilos de Aprendizaje, 9(18), 205-223. http://learningstyles.uvu.edu/index.php/jls/article/view/324/222

Hernández, I., Recalde, J., \& Luna, J. A. (2015). Estrategia didáctica: una competencia docente en la formación para el mundo laboral. Revista Latinoamericana de Estudios Educativos, 11(1), 73-94. http://www. redalyc.org/articulo.oa?id=134144226005

Kemmis, S., \& Mctaggart, R. (1988). Cómo planificar la investigaciónacción. Laertes.

Mansilla, J., \& Beltrán J. (2013). Coherencia entre las estrategias didácxticas y las creencias curriculares de los docentes de segundo ciclo, a partir de las actividades didácticas. Perfiles Educativos, XXXV(19), 25-39. https://core.ac.uk/download/pdf/143612196.pdf

Merellano-Navarro, E., Almonacid-Fierro, A., Moreno-Doña, A., \& CastroJaque, C. (2016). Buenos docentes universitarios: ¿Qué dicen los estudiantes? Educação e Pesquisa, 42(4), 937-952. https://doi. org/10.1590/S1517-9702201612152689 
Munarriz, B. (s.f.). Técnicas y métodos en Investigación cualitativa. Universidad del País Vasco. https:/ruc.udc.es/dspace/bitstream/ handle/2183/8533/CC-02art8ocr.pdf?sequence=1\&isAllowed=y

Muñoz,C., Andrade, M.C., \& Cisneros M. (2011). Estrategias deinteracción oralenelaula:una didácticacrítica deldiscursoeducativo.Magisterio Editorial. http://media.utp.edu.co/referencias-bibliograficas/ uploads/referencias/libro/libro-estrategias-de-interaccion-oral-enel-aulapdf-dxFfU-libro.pdf

Organización de las Naciones Unidas para la Educación, la Ciencia y la Cultura. (2008). Política, legislación y administración escolar. UNESCO.

Rivero, I., Gómez, M., \& Abrego R. (2013). Tecnologías educativas y estrategias didácticas: criterios de selección. Revista Educación y Tecnología, 3, 190-206.

Rojas, A. R. (2009). La Didáctica Crítica, critica la crítica educación bancaria. Revista Integra Educativa, 2(1), 93-108. http://www. scielo.org.bo/pdf/rieiii/v2n1/n01a06.pdf

Universidad Autónoma de Baja California. (s.f.). Facultad de Derecho Mexicali. http://derecho.mxl.uabc.mx/derecho/\#

Universidad Autónoma de Baja California. (2018). Modelo educativo de la UABC 2018. http://www.uabc.mx/formacionbasica/documentos/ ModeloEducativodelaUABC2018.pdf

Universidad Autónoma de Baja California. (2019). Facultad de Derecho Mexicali. Plan de Desarrollo 2017-2021. http://derecho.mxl.uabc. $\mathrm{mx} / \mathrm{derecho/doc/pd/plan \_ 2017 \_ 2021.pdf}$

Villarreal-Treviño, M. M. (2006). La importancia de las estrategias de enseñanza en el logro del aprendizaje en alumnos universitarios (Tesis de maestría). Instituto Tecnológico y de Estudios Superiores de Occidente (ITESO), Tlaquepaque, Jalisco. http://hdl.handle. net/11117/3945 


\section{Capítulo 4}

\section{Desarrollo de estrategias didácticas para promover el aprendizaje significativo en preparatoria abierta}

Ana Teresa Quintero Pacheco y Francisco Javier Arriaga Reynaga

La educación abierta es aquella en la que se prescinde del aula y de la presencia de profesores, y cuyo proceso de enseñanza-aprendizaje se lleva a cabo con materiales escritos programados (Loza, 1997; Messina, 2003; Ramos 2014), de esta manera personas mayores de 15 años pueden ingresar. Este tipo de educación brinda a los jóvenes y adultos la oportunidad de iniciar o continuar sus estudios en el nivel medio superior; es una opción ideal para quienes por alguna razón no concluyeron sus estudios en el tiempo que les correspondía, de acuerdo con los estándares normalizados socialmente, donde a cada etapa escolar corresponde un rango de edad. Por ello, es fundamental contar con instancias que apoyen a esta población con niveles educativos desfasados para que adquieran los conocimientos necesarios y obtengan mayores oportunidades; asimismo, se debe contar con subsistemas, como estrategia principal para el apoyo de los jóvenes y adultos (Londoño, 1995; Medina, 2000; Osorio, 2003).

En el caso específico de la preparatoria abierta, aunque se considera una buena opción, se han visto distintas desventajas, ya sea porque no hay suficientes centros para dar asesorías o por el desconocimiento de 
su existencia; al respecto, Larentes-da Silva (2018) menciona que hay un "papel central de los asesores en el trabajo con jóvenes y adultos, los innumerables esfuerzos que hacen por enseñar lo que saben y cómo su condición de asesores también contribuye para cambiar sus vidas" (p.185). Así, en los docentes existe la motivación de enseñarles y apoyarlos de la mejor manera, a través de los conocimientos y herramientas con las que cuentan.

En la innovación de estrategias para propiciar el aprendizaje, el docente es uno de los protagonistas, pues "para ejercer eficazmente su desempeño, necesita apoyarse en estrategias creativas a fin de coadyuvar al logro de un aprendizaje significativo en los estudiantes" (Reyes et al., 2014, p.58). Dicho lo anterior, es necesario aprovechar las experiencias adquiridas por los estudiantes y relacionarlo con el conocimiento nuevo, para que los contenidos tengan sentido para ellos. Lo importante de generar la dinámica del aprendizaje significativo en los alumnos es que se deje a un lado la memorización y se opte por aplicar los conocimientos según su contexto.

Las estrategias didácticas tienen un propósito, la decisión para su aplicación deben tener un objetivo, por lo que en la educación de jóvenes y adultos no es la excepción. Generar estrategias didácticas para desarrollar el aprendizaje significativo beneficia tanto a alumnos como a docentes, al permitir dinámicas de interacción, donde el docente guía los temas y anima a participar a los estudiantes (Díaz Barriga \& Hernández, 2002; Garibay, 2011); estos últimos, al participar con sus comentarios y experiencias, benefician la clase porque crean conexiones entre lo que sucede en su vida cotidiana y los contenidos temáticos.

Al utilizar estrategias didácticas en el aula, se facilita el aprendizaje de los estudiantes; por ejemplo, una planeación que fomente el aprendizaje significativo —el cual consiste en la conexión del conocimiento 
previo y el nuevo- permite que el nuevo conocimiento adquiera significado para la persona que está aprendiendo (Moreira, 2005; Nieva \& Martínez, 2019; Romero, 2009) y, por lo tanto, haya una comprensión y retención del conocimiento.

En el proceso de enseñanza-aprendizaje es importante idear estrategias que permitan a los alumnos aprender los contenidos temáticos de los módulos, no solo para aprobar un examen sino para que el aprendizaje sea significativo, esto permitirá que los estudiantes no solo memoricen los temas, también que los analicen y generen sus propias ideas (Acosta \& Boscán, 2012; González, 2001). Jóvenes y adultos tienen un proceso de aprendizaje que no se puede comparar con estudiantes en un nivel escolarizado, adecuar los temas a sus necesidades permitirá que el aprendizaje se vuelva significativo, pues tendrá una utilidad para su contexto, más allá de la memorización del contenido para aprobar un examen.

Con referencia a lo anterior, el material que se utilice para promover el aprendizaje significativo es parte de las estrategias didácticas, por lo que:

Es importante que los docentes conozcan, comprendan y asimilen las características del material didáctico para que propicien ambientes de aprendizajes significativos dentro del aula, que se valgan de lo que hay en su medio para diversificar las formas de aprendizaje y creen ambientes agradables, activos y significativos en la formación del discente. (Manrique \& Gallego, 2012, p.107)

Los docentes al apoyarse en materiales para crear estrategias que desarrollen aprendizajes significativos crean un ambiente propicio para los estudiantes; un lugar donde quieren estar, pero sobre todo un espacio para aprender. 
Las estrategias didácticas son ese medio que los docentes pueden adquirir para transmitir el conocimiento. Según Jiménez y Robles (2016):

las estrategias didácticas como elemento de reflexión para la propia actividad docente, ofrecen grandes posibilidades y expectativas de mejorar la práctica educativa. El docente para comunicar conocimientos utiliza estrategias encaminadas a promover la adquisición, elaboración y comprensión de los mismos. (p.108)

El docente, al ser responsable de la creación e innovación de su clase, tiene la posibilidad de apoyarse en este recurso, que cambie por completo la perspectiva de la enseñanza y logre el objetivo más importante dentro de la educación, el aprendizaje de los alumnos.

Actualmente, a los docentes no se les exige una formación profesional docente para impartir clases en preparatoria abierta; se incentiva a que se trabaje por medio de memorización de guías de estudio y, por lo general, los estudiantes son conducidos a una lectura intensiva de memorización; esto provoca la ocurrencia de un bajo nivel de interés que a la postre desencadena en situaciones de bajo rendimiento y, en casos extremos, a la deserción escolar.

Esta cuestión es importante, pues cada día hay más jóvenes y adultos, a quienes no les ha sido posible concluir los estudios a nivel medio superior y se interesan por terminarlos, pero si esta modalidad no les brinda una opción efectiva para aprender, pudiese causar que se pierda el interés por continuar los estudios.

Es importante que pongan al alcance de las personas información sobre las distintas modalidades que existen para terminar sus estudios, asimismo, si lo requieren, formación y capacitación, ya que se corre el 
riesgo de que los conocimientos, habilidades y destrezas no sean congruentes con los certificados escolares; es decir, que haya personas con certificado, pero sin competencias de egreso, las cuales deberían tener por haber terminado sus estudios de bachillerato. Es por esto, que las autoridades educativas consideran darle más importancia a la enseñanza abierta del nivel medio superior, fortalecer los planes de clase con estrategias de enseñanza pertinentes para este segmento de población, mejorar y modernizar la didáctica en las clases — de tal manera que los estudiantes se interesen en aprender y no solo en obtener un certificado- y lograr que el aprendizaje sea pertinente para verterlo en las problemáticas auténticas de la sociedad.

Para resolver esta problemática, una de las posibilidades es la experimentación de alternativas pedagógicas, en el sentido de probar y evaluar estrategias didácticas innovadoras, para identificar las cualidades y, sobre todo, los beneficios intelectuales y de aplicación. En este sentido, es posible buscar una selección de este tipo de acciones pedagógicas que prueben ser efectivas para influir en el interés e involucramiento real de los estudiantes de preparatoria abierta.

Dado lo anterior, se realizó un estudio con el objetivo de proponer un programa de estrategias didácticas para promover el desarrollo del aprendizaje significativo en estudiantes de preparatoria abierta. Para lograrlo, primero se exploraron las características de la instrucción que reciben los participantes y con ello identificar los tipos de estrategias que se emplean respecto a las clases que reciben, con el fin de obtener un diagnóstico sólido que permitiera diseñar dicho programa. En este capítulo, se presentan los resultados de esta fase diagnóstica. 
Capítulo 4

\section{Método}

\section{Contexto}

La Preparatoria Abierta Hispana se fundó en 1994 en la ciudad de Mexicali, Baja California, México. Está ubicada en Bulevar Lázaro Cárdenas \#958 en la colonia Villas de la República. Se caracteriza por tener un alumnado de jóvenes y adultos, provenientes de las colonias, Villas de la República, Villa Florida, Condesa, Pedregal y Villa Verde. A partir del 2010, ofrece los siguientes servicios: asesoría para aprobar los exámenes del Plan Nuples, asesorías individuales de cualquier nivel educativo, formación y asesoría a alumnos que decidan obtener su certificado de preparatoria a través del examen CENEvAL.

Con respecto a la infraestructura, la escuela cuenta con una oficina para la directora, un salón donde se ofrecen las asesorías individuales, un salón amplio donde los alumnos de preparatoria abierta toman clases, un baño y un área de estacionamiento. Respecto al mobiliario se tienen dos pizarrones, dos mesas y diez mesabancos. La escuela no es grande, pero tiene espacio suficiente para atender a una matrícula de 35 alumnos en sus diferentes horarios: lunes a jueves de 8 a $10 \mathrm{am}$, lunes y miércoles de 6 a 8 pm y sábados de 1 a 5 pm. El turno vespertino tiene la mayor matrícula de la escuela y el sabatino la menor.

\section{Tipo de investigación}

La investigación es de tipo cualitativo; profundiza en las interacciones de los participantes y rescata la esencia de la realidad de aquellos que la experimentan (Álvarez, 2003). Se contempló el método de investigación-acción, que "es un proceso que capacita a las personas prácticas a desarrollar una mejor comprensión del conocimiento en la acción” (Latorre, 2002, p.19). Este tipo de método fue seleccionado porque: 
Se relaciona con los problemas prácticos cotidianos experimentados por los profesores, en vez de con los "problemas teóricos" definidos por los investigadores puros en el entorno de una disciplina del saber. Puede ser desarrollada por los mismos profesores o por alguien a quien ellos se lo encarguen. (Elliot, 2000, p.5)

El método de investigación-acción resultó ser ideal porque se enfoca en los problemas de enseñanza que pueden existir dentro del aula. Este método es fundamental porque "la investigación-acción interpreta 'lo que ocurre' desde el punto de vista de quienes actúan e interactúan en la situación problema, por ejemplo, profesores y alumnos, profesores y director" (Elliot, 2000, p.5).

\section{Participantes}

La muestra del estudio estuvo conformada por los estudiantes de los turnos matutino y sabatino. Se seleccionaron estos alumnos por la disposición de la escuela para trabajar con ellos. Por lo tanto, los participantes quedaron constituidos por un total de nueve estudiantes: seis del turno matutino y tres del sabatino. En la tabla 1 se presenta información de los participantes.

\section{Técnicas de recolección de datos}

Se utilizó la técnica de observación, porque "implica adentrarnos profundamente en situaciones sociales y mantener un papel activo, así como una reflexión permanente. Estar atento a los detalles, sucesos, eventos e interacciones” (Hernández-Sampieri et al., 2014, p.399). Al momento de observar, se rescataron las opiniones de los participantes con respecto a las clases, la forma como enseñan sus profesores y la manera como se están aplicando las estrategias. 


\section{Tabla 1}

\section{Información de los participantes}

\begin{tabular}{cccccc}
\hline Participante & Sexo & Edad & $\begin{array}{c}\text { Tiempo de estudiar } \\
\text { la preparatoria }\end{array}$ & Trabaja & Lugar de trabajo \\
\hline 1 & Hombre & 18 & 6 meses & Sí & Tienda de juegos \\
\hline 2 & Mujer & 24 & 8 meses & Sí & Vender ropa por Internet \\
\hline 3 & Mujer & 25 & 2 meses & Sí & Birriería \\
\hline 4 & Hombre & 16 & 10 meses & Sí & Tienda de juegos \\
\hline 5 & Hombre & 18 & 2 meses & Sí & Tienda de abarrotes \\
\hline 6 & Hombre & 18 & 2 meses & Sí & Fábrica \\
\hline 7 & Mujer & 18 & 3 meses & Sí & Fábrica \\
\hline 8 & Mujer & 19 & 6 meses & Sí & Fábrica \\
\hline 9 & Mujer & 16 & 1 mes & No & -
\end{tabular}

Para conocer más a fondo sobre las opiniones de los alumnos con respecto a la forma como se imparten las clases y otras situaciones, se optó por utilizar la entrevista, la cual consiste en "una conversación que tiene una estructura y un propósito. En la investigación cualitativa, la entrevista busca entender el mundo desde la perspectiva del entrevistado y desmenuzar los significados de sus experiencias" (Álvarez-Gayou, 2009, p.109).

\section{Procedimiento}

Respecto a la observación participante se trabajó con una bitácora, anotando los acontecimientos más relevantes dentro del aula, especialmente los siguientes aspectos: (a) participación de los estudiantes en clase, (b) pláticas informales y (c) opinión de los estudiantes respecto a las clases y exámenes. 
La bitácora se utilizó todos los días que se impartió el módulo, durante un mes aproximadamente; de esta manera, se pudo hacer una comparación de los factores que intervienen en el proceso de enseñanza-aprendizaje, con mayor precisión al momento de realizar el análisis de resultados.

Sobre el diseño de la entrevista semiestructurada, se realizaron las siguientes siete preguntas:

1. ¿Podrían decirme si ustedes trabajan? De ser afirmativo ¿en qué trabajan?

2. ¿Cuánto tiempo le dedican a estudiar? (especificar horas, minutos etc.)

3. ¿Qué opinas de las clases de preparatoria abierta?

4. ¿Los temas que aprendes, consideras que tienen alguna relación con tu vida cotidiana? ¿Me puedes dar algunos ejemplos?

5. ¿Te gusta la forma en que tus maestros te enseñan? ¿Qué te gustaría que cambiara? (en caso de que la respuesta sea no)

6. ¿La manera en que te enseñan tus profesores, te ha permitido aprender los temas que se ven en preparatoria abierta?

7. ¿Piensas que, al estar estudiando la preparatoria abierta, tienes muchas posibilidades de ingresar a una carrera universitaria?

La entrevista giró en torno a las clases, la forma como los docentes explican y evalúan y si ellos identifican claramente las diferencias que existen con otro tipo de modalidades. También se preguntó sobre los temas que han estudiado en preparatoria abierta y si consideraron que existe una relación con los diferentes ámbitos de su vida, si creyeron que tienen relación con su trabajo o con lo que ellos desean estudiar, si tienen interés de ingresar a un nivel superior y qué tan preparados se siente para el examen de ingreso, por último, si consideran que el sistema abierto les da una preparación suficiente para ingresar a la universidad. 
Capítulo 4

\section{Análisis de resultados}

Se presentan los resultados del diagnóstico, partiendo de los datos obtenidos, preguntas realizadas en la entrevista y una comparación con lo observado en clase. Después, se identifican las opiniones de los alumnos con respecto a sus profesores de preparatoria y se señala de qué manera han servido las clases para su formación académica y profesional.

\section{Estrategias didácticas utilizadas en preparatoria abierta}

Para identificar si en preparatoria abierta se utilizan estrategias didácticas para desarrollar el aprendizaje significativo en los alumnos, se procedió a realizar una entrevista grupal con cinco alumnos. Con las siete preguntas se recogió información sobre la opinión de los estudiantes con respecto a qué les parecen sus clases, la manera en que el profesor impartió el módulo, qué tanto consideran que aprendieron los contenidos de los módulos impartidos por el docente y si se consideran preparados para continuar sus estudios en un nivel superior.

En una de las preguntas, se solicitó su opinión sobre cómo consideran que se aprende en preparatoria abierta.

Entrevistador: ¿Qué opinas de las clases de preparatoria abierta?

Sujeto 1: explican mejor, se meten más en los temas.

Sujeto 2: Están mejor que las de la prepara normal, explican mejor.

Sujeto 3: Yo digo que se me hace bien por parte de las materias son más rápidas porque te explican mejor.

En otra de las preguntas de la entrevista, manifestaron algunas opiniones con respecto a los docentes, que a pesar de decir que les gustaban, señalaron a uno en específico diciendo que es muy rápido para explicar los temas. Por lo tanto, fue pertinente saber qué les gustaría que 
el docente hiciera. Por lo expresado, se infiere que los estudiantes están insatisfechos con uno de los docentes.

Entrevistador: ¿En ese uno, que cambiarías?

Sujeto 3: Que sea más directo, que diga menos “chicos” ... Que vaya más lento de lo que va actualmente, porque los temas en sí se hacen más largos y todos los días, todos nos estamos durmiendo en clase.

Las actividades que realizan los docentes en el aula de preparatoria abierta son muy importantes, pues al no disponer del tiempo suficiente para explicar los temas, es necesario que las horas que son presenciales sean fructíferas, de esta manera los estudiantes tendrían claros los temas y podrían seguir practicando en casa. En caso de que no sucediera de tal manera, sería muy difícil lograr que aprendieran el contenido de los módulos que ven en su clase.

Entrevistador: ¿La manera como te enseñan tus profesores te ha permitido aprender los temas que miras en preparatoria?

Sujeto 1: Con usted si

Sujeto 5: Algunos

Entrevistador: Por ejemplo, con el caso de los que no ¿Qué es lo que hacen?

Sujeto 4: También en cuestión en cómo explica, no se entiende tan bien.

Es importante que las estrategias didácticas ayuden a generar dinamismo en las clases, que se aprenda de una manera fácil, pero que se ajusten a sus necesidades. Como se explica en la teoría del aprendizaje 
de adultos, a estos nos les gusta ser tratados como niños (Rogers \& Uddin, 2005). Además, si no sienten la confianza para seguir preparándose, resultará difícil que quieran ingresar a un nivel superior.

Entrevistador: ¿Piensas que al estar estudiando la preparatoria abierta tienes muchas posibilidades de ingresar a una carrera universitaria?

Sujeto 4: No, porque como va muy rápido la materia siento que no las aprendo bien, si voy a salir preparado, pero no tanto como para una carrera universitaria.

Sujeto 3: Solo para ir a la maquila.

Dicho lo anterior, se considera que, es importante implementar estrategias que ayuden a los estudiantes a lograr un aprendizaje significativo y sientan la confianza de continuar con sus estudios, que el contenido temático les sirva no solo para aprobar exámenes, sino para que lo apliquen en sus diferentes actividades y no crean que la preparatoria abierta no los prepara para la universidad.

\section{Actividades para desarrollar aprendizaje significativo}

El aprendizaje significativo permite realizar conexiones entre la experiencia y el contenido nuevo, de tal manera que cree una comprensión entre lo cognitivo y lo experiencial (Díaz-Barriga \& Hernández, 2002). Es por esto, que es conveniente saber qué actividades se realizan en preparatoria abierta que fomenten el aprendizaje significativo en los alumnos.

Entrevistador: ¿Los temas que aprenden consideran que tienen relación con su vida diaria?

Sujeto 4: No, porque no voy a pedir medio tomate haciendo una ecuación matemática. 
Capítulo 4

Entrevistador: ¿Alguien me podría decir un ejemplo de cómo un tema se puede relacionar con su vida diaria?

Sujeto 3: No, porque no es como que le ponga mucha atención a lo que está pasando alrededor de mi vida, me vale, dejo que todo fluya, qué me importa.

Se observó que a los estudiantes se les dificulta ejemplificar situaciones donde pudieran aplicar lo que están viendo en clase, en otras ocasiones, se les pedía que ellos contaran algo sobre cómo creen que pudieran identificar los temas y tampoco resultó.

\section{Conclusión}

El uso de estrategias didácticas ha sido parte fundamental para el trabajo y desarrollo del proceso enseñanza-aprendizaje en el aula; “consideramos que el docente debe poseer un bagaje amplio de estrategias, conociendo qué y cómo pueden utilizarse o desarrollarse ampliamente" (Díaz-Barriga \& Hernández, 2002, p.141). Por lo tanto, es importante conocer cuáles son las estrategias apropiadas para la clase y el propósito de su utilización, para que el docente esté preparado al momento de estar frente al grupo, sin olvidar que la intención es que los estudiantes aprendan.

Con las estrategias didácticas se busca lograr que los estudiantes sean críticos con el contenido que se enseña (Sánchez, 2010), esto quiere decir, que el docente debe buscar aquellas estrategias que induzcan a los estudiantes a reflexionar sobre las temáticas, analizarlas y relacionarlas con su contexto; sin embargo, la realidad es otra.

Con respecto a las estrategias didácticas utilizadas en preparatoria abierta, se llegó a la conclusión de que son repetitivas; solo utilizan el cuestionario para memorizar respuestas y repasar las guías de estudio en 
clase, esto causa que las sesiones sean monótonas y que los estudiantes se enfoquen en aprobar el examen - no en aprender-; y, cuando esto no sucede, los alumnos se desmotivan y desertan de la escuela. Por lo tanto, es necesario implementar estrategias didácticas que promuevan el aprendizaje significativo, para dar diversidad al proceso de enseñanza-aprendizaje y asegurarse de que los estudiantes realmente aprendan.

Los docentes deben utilizar estrategias que les permita adaptar el contenido, de tal manera que los estudiantes puedan construir los aprendizajes y, en consecuencia, realizar la subsecuente transferencia, de una manera más fácil y efectiva (Acosta \& Boscán, 2012). Es importante que se planteé a los profesores de preparatoria abierta sobre lo fundamental que es innovar en el aula a través de las estrategias didácticas, pues los contenidos no solo deben ser memorizados sino comprendidos y analizados por los estudiantes para que el aprendizaje se vuelva significativo.

Para Manterola (1998), "el aprendizaje significativo se produce, en cambio, cuando los nuevos contenidos pueden relacionarse de un modo sustantivo con los conocimientos previos y cuando se tiene una actitud favorable hacia el contenido que permite darle significado” (p.181).

Por consiguiente, es importante realizar una propuesta de intervención para que las formas de impartir las clases cambien, seleccionando estrategias didácticas que promuevan el aprendizaje significativo. La intención es trabajar un módulo con dichas estrategias, para saber de qué manera responden los estudiantes, si les es más sencillo aprender y aplicar lo visto en su vida personal y laboral; dependiendo de los resultados de dicha intervención, se compartiría con los docentes para que esto se replique y todos los módulos fomenten el aprendizaje significativo a través de las estrategias didácticas.

Por último, es importante mencionar que es necesario conocer mejor a la población de preparatoria abierta, que los estudiantes de esta modalidad 
reciban educación de calidad y que se promueva una mayor participación por parte de los docentes para cambiar la didáctica o intervención en el aula. La modalidad abierta debe tener una mayor proyección, pues hoy en día brinda una oportunidad para que las personas se preparen, sean competentes en el campo laboral y contribuyan al desarrollo económico del país. 
Capítulo 4

\section{Referencias}

Acosta, S., \& Boscán, A. (2012). Estrategias cognoscitivas para la promoción del aprendizaje significativo de la Biología, en la Escuela de Educación. Telos, 14(2), 175-193. https://www.redalyc.org/ articulo.oa?id=99323311002

Álvarez,J.(2003). Cómo haceruna investigación cualitativa.Fundamentos y metodología ( $1^{\mathrm{a}}$ ed.). Paidós.

Álvarez-Gayuo, J. (2009). Cómo hacer investigación cualitativa. Fundamentos y metodología (1 $1^{\mathrm{a}}$ ed.). Paidós.

Díaz-Barriga, F., \& Hernández, G. (2002). Estrategias docentes para un aprendizaje significativo. Una interpretación constructivista $\left(2^{\mathrm{a}}\right.$ ed.). McGraw-Hill

Elliot, J. (2000). La investigación-Acción en Educación (4 ${ }^{\mathrm{a}}$ ed.). Morata.

Garibay, M. (2011). El foro virtual como recurso integrado a estrategias didácticas para el aprendizaje significativo. Virtualidad, Educación y Ciencia, 2(2), 89-96. https://revistas.unc.edu.ar/index.php/vesc/ article/view/336

González, R. (2001). Factores que inciden en la aplicación de estrategias didácticas docentes para el aprendizaje significativo del alumno de educación básica. Telos, 3(2), 193-210. https://dialnet.unirioja.es/ servlet/articulo?codigo $=6436481$

Hernández-Sampieri, R., Fernández, C., \& Baptista, P. (2014). Metodología de la Investigación (6 ed.). McGraw-Hill.

Jiménez, A., \& Robles, F. (2016). Las estrategias didácticas y su papel en el desarrollo de enseñanza aprendizaje. Revista EDUCATECNOCIENCIA, 9(10), 106-113. http://tecnocientifica. com.mx/educateconciencia/index.php/revistaeducate/article/ view/16/142 
Larentes-da-Silva, A. (2018). Paulo Freire, el INEA y la educación de jóvenes y adultos en México. Iisue, IX(24), 173-188. http://www. scielo.org.mx/pdf/ries/v9n24/2007-2872-ries-9-24-173.pdf

Latorre, A. (2002). La investigación-Acción. Conocer y cambiar la práctica educativa ( $1^{\mathrm{a}}$ ed.). Colofón.

Londoño, O. (1995). Hacia una nueva institucionalidad en educación de jóvenes y adultos ( $1^{\mathrm{a}}$ ed.). UNESCO. https://unesdoc.unesco.org/ ark:/48223/pf0000115559

Loza, J. (1997). Notas sobre la educación continua, abierta y a distancia. Revista de la Educación Superior, (104), 1-13. http://publicaciones. anuies.mx/revista/104/1/3/es/notas-sobre-la-educacion-continuaabierta-y-a-distancia

Manrique, A. M., \& Gallego, A. M. (2013). El material didáctico para la construcción de aprendizajes significativos. Revista Colombiana de Ciencias Sociales, 4(1), 101-108. https:/www.funlam.edu.co/ revistas/index.php/RCCS/article/view/952/874

Manterola, M. (1998). Psicología Educativa: Conexiones con las salas de clase. Material de apoyo a la docencia No. 5. http://bibliotecadigital.ucsh.cl/greenstone/collect/libros_LR/archives/HASH0119. dir/Psicologia\% 20educativa.pdf

Medina, O. (2000). Especificidad de la educación de adultos. Bases psicopedagógicas y señas de identidad. UNED, EDUCACIÓN XX1, 3(4), 91-140. http://revistas.uned.es/index.php/educacionXX1/ article /view/406

Messina, G. (2003). Educadores de adultos: Acerca del proceso de su formación. Decisio (5), 3-11. https://cdn.crefal.org/CREFAL/ revistasdecisio/decisio5.pdf

Moreira, M. (2005). Aprendizaje significativo crítico. Indivisa. Boletín de estudios e investigación, (6), 83-102. https://www.redalyc.org/ articulo.oa?id=77100606 
Nieva, J., \& Martínez, O. (2019). Confluencias y rupturas entre el aprendizaje significativo de Ausubel y el aprendizaje desarrollador desde la perspectiva del enfoque histórico cultural de L. S. Vygotsky. Revista Cubana de Educación Superior, 38(1). http://scielo.sld.cu/ pdf/rces/v38n1/0257-4314-rces-38-01-e9.pdf

Osorio, J. (2013). Desafíos docentes en la educación de jóvenes y adultos en chile: hacia una agenda de conversaciones para el diseño e implementación de nuevas políticas. Temas de Educación, 19(1), 57-66. https://revistas.userena.cl/index.php/teduacion/article/ view/380

Ramos, J. (2014). Situación educativa de la población joven y adulta de América Latina y el Caribe Su unidad/diversidad. Revista Interamericana de Educación de Adultos, 36(1), 10-36. http://www. redalyc.org/articulo.oa?id=457545087002

Reyes, F., Vera, L., \& Colina, E. (2014). Estrategias creativas para promover el aprendizaje significativo en la práctica docente simulada. Opción, 30(75), 55-74. www.redalyc.org/articulo.oa?id=31035400002

Rogers, A., \& Uddin, A. (2005). Adults learning literacy. En B. V. Street (Ed.), Literacies across Educational Contexts: Mediating Learning and Teaching (pp. 235-260). Caslon.

Romero, F. (2009). Aprendizaje significativo y constructivismo. Revista Digital para Profesionales de la Enseñanza, (3). https://www. feandalucia.ccoo.es/docu/p5sd4981.pdf

Sánchez, A. (2010). Estrategias didácticas para el aprendizaje significativo de los contenidos de trigonometría empleando TIC. Revista Electrónica de Tecnología Educativa, (31), 1-19. https://www. edutec.es/revista/index.php/edutec-e/article/view/443 


\section{Capítulo 5}

\section{La enseñanza de la danza folclórica en un entorno multidisciplinar y virtual}

Gloria Patricia Olguín Reyes, Aidee Espinosa Pulido

y Maria Amparo Oliveros Ruiz

La danza es el arte de expresar sentimientos, emociones y pensamientos, estimulando varios sentidos del cuerpo - entre ellos, la vista, el tacto y el oído- y tiene como resultado el desarrollo de la expresión corporal (Ballestero, 2018). Según Barnes (2003, como se citó en Galla, 2018), "La expresión corporal/danza tiene como objeto que cada intérprete encuentre su propia forma de moverse y que su bagaje de movimiento sea cada vez mayor y más diverso” (p.21).

La danza es una de las primeras actividades realizadas por el ser humano desde el principio de la historia; a lo largo de los siglos se ha diversificado y se han desarrollado múltiples estilos, entre ellos, el folclore.

La palabra folclore proviene del inglés folklore compuesta por la palabra folk que significa pueblo y la palabra lore que significa saber, es decir, etimológicamente significa "el saber del pueblo". El término fue utilizado por primera vez, en 1846, por William Thoms, quien acuñó esta palabra para dar significado a esta disciplina artística, conceptua- 
lizada como "El saber tradicional de clases populares de las naciones civilizadas" (Barrera, 1997). A partir de lo anterior, podemos definir a la Danza folclórica mexicana como el conjunto de sentimientos, emociones y pensamientos por medio de movimientos dancísticos representativos del pueblo mexicano.

\section{Entorno virtual de aprendizaje}

Según Trejo (2013), "Un Entorno Virtual de Aprendizaje (EVA) es el conjunto de medios de interacción sincrónica y asincrónica, donde se llevan a cabo el proceso enseñanza y aprendizaje, a través de un sistema de administración de aprendizaje” (p.1). Los Eva han tenido gran impacto en estos procesos. "Dentro de sus opciones representativas se destacan la flexibilidad y la usabilidad” (p.1), además del uso de las tecnologías de la información.

Los beneficios que aporta un EvA están relacionados con la democratización del acceso a la oferta educativa, la reducción de costos con el uso de modelos educativos basados en TIC y la consolidación de la Educación a Distancia, la mejora de la calidad de los docentes y potenciación del desarrollo de competencias para el mundo laboral en el uso de la TIc. (Trejo, 2013, p.1)

La educación a distancia se puede asumir como una modalidad educativa que se caracteriza por el uso de medios tecnológicos e impresos, a través de los cuales se hacen llegar los contenidos educativos a los estudiantes y estos a su vez lo aprenden a su manera, de una forma independiente, en donde el docente además funge como orientador y guía (Acosta, 2009). 
Capítulo 5

\section{Ámbito educativo internacional}

Internacionalmente, las artes han adquirido gran relevancia en cuanto a su ejecución en los ámbitos sociales y educativos. Las nuevas formas de aprender enfocadas en el constructivismo y la innovación les dan una base a las nuevas corrientes pedagógicas (Ruiz, 2017).

La Organización de las Naciones Unidas para la Educación, la Ciencia y la Cultura (UNESCO) funge como pilar a nivel internacional en la promoción de las artes, la educación artística y las expresiones culturales, entre otras; mediante múltiples convenciones acerca de estos temas que dan apertura para el desarrollo de estas disciplinas.

A través de la Hoja de Ruta para la educación artística, la onU (2006) presenta la importancia de la educación artística en la educación; este documento hace una recopilación normativa de la Declaración Universal de los Derechos Humanos y la Convención sobre los Derechos del Niño, en las cuales se menciona el derecho a la participación en la vida cultural. Respecto a los niños, se indica que su educación deberá estar encaminada a "Desarrollar la personalidad, las aptitudes y la capacidad mental y física [...] hasta el máximo de sus posibilidades” (p.2). Además, se decreta una ruta para la integración de la formación artística en la educación formal e informal.

\section{Ámbito educativo nacional}

La educación es uno de los primeros derechos expresados en la Constitución Política de los Estados Unidos Mexicanos (1917), particularmente en el artículo tercero, que incluye, entre otras, la enseñanza de las artes como parte del currículo en educación básica. Por otra parte, en su artículo segundo, reconoce y garantiza el derecho de los pueblos indígena, resaltando la importancia de preservar sus costumbres y tradiciones, garantizar su educación, definir y desarrollar programas educativos de 
contenido regional que reconozcan la herencia cultural, así como impulsar el respeto y conocimiento de las diversas culturas existentes en la nación.

Además de reconocer a las artes como una disciplina formativa en el adolescente, la Secretaría de Educación Pública (SEP, 2017) proporciona herramientas para la enseñanza de estas disciplinas, dando la libertad para diseñar situaciones educativas con las que se permitan experimentar procesos de producción artística, el desarrollo del pensamiento artístico y la valoración de las relaciones con la cultura y el arte.

Se sugiere emplear una perspectiva lúdica, independientemente del nivel. El juego, aun entre los adolescentes, permite la resolución de problemas y retos de una forma agradable y divertida, lo que también contribuye al desarrollo cognitivo y promueve de manera activa la exploración de las emociones. (SEP, 2017, p.11)

\section{La danza como medio educativo}

La consideración de la danza como medio educativo, pensando en una educación formadora y desarrolladora, permite la posibilidad de estimular diversas capacidades y habilidades para acceder a otro tipo de aprendizajes que demanda el proceso educativo (Ferreira, 2009).

La danza folclórica había sido por muchos años, como lo mencionó Martínez (2007), una actividad constante en la educación secundaria, que se integraba en la materia de artes. En la actualidad, suele estar presente solo en eventos escolares para conmemorar fechas históricas y culturales, por lo que la formación de un grupo dancístico es casi nula.

La educación artística forma parte del plan curricular en nivel secundaria (SEP, 2017); el arte consta de áreas como la música, el teatro, la 
danza y la escultura; por ello, el campo de conocimiento es amplio, lo que conlleva a que la especialización del docente se vuelva compleja, es decir, un maestro de artes no necesita conocer todas las artes para poder impartir una clase, derivado de esto, la formación del docente es cada vez más carente en las disciplinas dancísticas, por lo que esta actividad se vuelve menos recurrente en la educación artística.

Actualmente, gracias a la apertura de la autonomía curricular (Estrada, 2017; García \& Stalin, 2005; SEP, 2018), el docente no está obligado a impartir la danza.

\begin{abstract}
Algunos consideran la educación artística como una actividad destinada a llenar los espacios de tiempo libre, como una actividad puramente recreativa. Mismo estatus guarda la denominada educación física. Con esta concepción, se minimiza el verdadero sentido de la educación artística y con ello, la pérdida de su esencia y significado. Marginar a la educación artística es nulificar sus aportaciones a la dimensión formativa del educando. (Tamés, 2004, p.77)
\end{abstract}

A partir de lo anterior, se realizó un estudio que planteó como objetivo general: Instruir la danza folclórica mexicana, a través de un taller de manera multidisciplinar. Enfocándose en otorgar una serie de herramientas para su aprendizaje, que beneficie a los alumnos de secundaria, favoreciendo su enseñanza integral. El trabajo de investigación partió de un diagnóstico.

El estudio se llevó a cabo en un centro educativo que se apoya en los grupos de danza ya establecidos para presentarlos en eventos sociales y culturales organizados por la institución, como resultado se ha acrecentado un desinterés de los alumnos por el aprendizaje de la danza 
folclórica mexicana. Esta situación provoca una pérdida de tradiciones regionales.

\section{Metodología}

La investigación en general se centró en un enfoque cualitativo, utilizando particularmente el ABP, que es una metodología que enfrenta a los participantes de estudio en situaciones en las que la toma de decisiones es vital para la solución de un problema, se realiza de manera colaborativa, entendiéndose al proyecto como un conjunto de actividades articuladas entre sí, con el objetivo de generar productos con vías a resolver problemas, satisfacer necesidades e inquietudes, considerando los tiempos asignados (Cobo \& Valdivia, 2017; Sánchez, 2013).

El АвP como estrategia didáctica es relevante en la experiencia educativa, pues permite: (a) el logro de aprendizajes significativos, al incluir objetivos y contenidos que van más allá de los planes curriculares; (b) la integración de asignaturas reforzando la educación transversal; (c) el fomento de la creatividad, la responsabilidad individual, el trabajo en equipo y pensamiento crítico, entre otros (Maldonado, 2008).

\section{Descripción del escenario}

La investigación se realizó en la escuela Secundaria 93 "Ignacio Sánchez Campos”, ubicada en el ejido Islas Agrarias (Valle de Mexicali), con una matrícula de 230 alumnos y con 33 empleados, conformados por docentes, directivos, administrativos, personal de apoyo e intendentes. La muestra fue no probabilística, se eligió de manera intencional como participantes a los alumnos de primer grado; considerando que "las primeras acciones para elegir la muestra ocurren desde el planteamiento mismo y cuando seleccionamos el contexto, en el cual esperamos encontrar los casos que nos interesan” (Hernández-Sampieri et al., 2014, p.394). 
Capítulo 5

\section{Diagnóstico educativo}

La investigación se sustentó partiendo de un diagnóstico (Hernández, 2015), construido con doce preguntas de opción múltiple, para contar con los elementos para diseñar un plan de intervención de acuerdo con los hallazgos proporcionados por las respuestas de los estudiantes, entre las que se destacan:

- Existe poco interés en los participantes por la danza folclórica.

- Los participantes afirman que no les gusta practicar danza folclórica.

- Pocos participantes aseguraron que en la escuela no se les enseña DFM.

- Los participantes refieren que prefieren otros ritmos para bailar como el Hip Hop y el Reggaetón.

- Los participantes afirman desconocer la danza.

- Alrededor de la mitad de los encuestados presentan interés en aprenderla.

Con los resultados anteriores se confirma que es necesario instruir la danza folclórica, por lo que se realizará la propuesta de un Taller como medio para una intervención educativa. Debido a la situación actual de emergencia sanitaria por la COVID-19, se optó por la enseñanza a través de un entorno virtual.

La propuesta de intervención se diseñó para lograr el acercamiento de los alumnos a la danza folclórica mexicana, utilizando esta disciplina de manera multidisciplinar, como una herramienta que coadyuve al aprendizaje de otras materias. Las actividades del taller serán dinámicas, orientadas a la expresión corporal y desarrollo de la creatividad (Martínez et al., 2014). 
Capítulo 5

\section{Plan de intervención: desarrollo del taller}

El taller se basa en el aprendizaje basado en proyectos (АВР). El diseño de intervención brindará herramientas y estrategias para el aprendizaje de la danza folclórica mexicana, a través de otras disciplinas como el dibujo, las artes escénicas, la música, así como otras áreas de conocimiento como la geografía y la historia; el diseño se enfoca en que los participantes se vean inmersos en una serie de actividades y retos que generarán la sana competencia y el trabajo en equipo.

El taller contiene un diseño de seis sesiones, dirigido a los alumnos de primer grado de secundaria, contiene actividades formativas para la danza folclórica mexicana, a través de una orientación multidisciplinar mediante el entorno virtual de aprendizaje, con soporte en la plataforma de Google Meet. En cada sesión se lanzará un reto a los equipos, que deberá ser cumplido en las próximas 24 horas. Los participantes tendrán la oportunidad de desarrollar actividades que deberán ser presentadas al docente mediante los grupos de contacto (tabla 1).

\section{Tabla 1}

\section{Taller (plan de intervención)}

\section{TALLER VIRTUAL DE DANZA FOLCLÓRICA MEXICANA:}

“QUE REVIVA EL FOLCLOR”

\section{Actividades Preliminares al inicio del taller.}

Cada equipo representará a alguno de los siguientes estados de la república: Baja California, Sinaloa, Nuevo León, Ciudad de México, Jalisco, Veracruz y Yucatán (se recomiendan estos estados debido al aporte cultural y ubicación geográfica)

\begin{tabular}{lc}
\multicolumn{1}{c}{ SESIÓN 1. } & RETO 1. \\
DANZA FOLCLÓRICA MEXICANA & "CREA TU VESTUARIO” \\
\hline - El docente crea una liga en Google Meet \\
$\begin{array}{ll}\text { que será enviada a los estudiantes partici- } \\
\text { pantes. }\end{array}$ & $\begin{array}{c}\text { Cada integrante del equipo deberá crear su traje tí- } \\
\text { pico con artículos y prendas que tengan en casa a } \\
\text { partir de una fotografía autorizada por el docente. }\end{array}$ \\
\hline
\end{tabular}


- Bienvenida a los alumnos.

- Tema “¿Qué es la danza folclórica mexicana y por qué es importante?” (introducción), el tema puede ser impartido por el docente creador o invitar a un experto en el tema.

- El docente explica las reglas del taller: Conformación de los equipos.

- Elección de un líder por equipo.

- Cada equipo crea un grupo de contacto donde estará todo el equipo y el docente para recibir indicaciones posteriores.

- Cada equipo tendrá que investigar el traje típico del estado que representa. El reto será lanzado una vez concluida la primera sesión y tendrá que ser cumplido dentro de las próximas 24 horas.

- Se crea para sociabilizar los proyectos una página de Facebook.
- El equipo contará con 24 horas para mandar un collage que deberá contener la foto original en la cual se basaron, el nombre del equipo y los vestuarios creados por los estudiantes, todo el equipo deberá participar en esta actividad.

- El docente publicará los collages de cada equipo en la página de Facebook.

- Una vez publicadas las fotos, los equipos contarán con 48 horas para obtener el mayor número de likes posibles.

- El criterio de premiación será 50\% creatividad en sus vestuarios y foto creada y el otro $50 \%$ por likes obtenidos.

* 1er. lugar - 100 puntos

* 2do. lugar - 50 puntos

* 3er. lugar - 25 puntos

- Cada actividad será evaluada por el docente (facilitador del taller) y dos docentes miembros del centro educativo o dos expertos en el tema.

\begin{tabular}{cc}
\hline SESIÓN 2. & RETO 2. \\
LA MÚSICA EN MÉXICO & “TOCA UN INSTRUMENTO” \\
\hline
\end{tabular}

- Se envía enlace de Google Meet a los equipos por medio de los grupos de contacto.

- Se presenta el tema “La Música en México” en donde el docente o el experto en el tema explica los diferentes estilos de música que existen en el país, con principal atención en los estados que participan.

- Se hará un material de consulta que será enviado a los grupos de contacto, con el objetivo de que los equipos puedan consultar la información para el reto que se les pedirá.
- El alumno consultará el material de apoyo en donde se especifica qué instrumentos son representativos de su región.

- El equipo elegirá una canción representativa de su estado, esta deberá ser aprobada previamente por el docente.

- El alumno creará un instrumento casero, pudiendo ser de viento, cuerda o percusión; el alumno está en la entera libertad de elegir qué instrumento crear.

- El alumno de manera individual se grabará con la canción elegida de fondo e intentando recrear los sonidos con el instrumento creado.

- El alumno deberá enviar el video al grupo de contacto.

- El docente podrá publicar los mejores videos en la página creada para divulgación.

- El criterio de evaluación será igual que en el reto 1, solo que esta vez solo será evaluada la creatividad del equipo al momento de presentar su video. 
Capítulo 5

\section{SESIÓN 3. \\ EL ESTADO QUE REPRESENTO \\ RETO 3. \\ “QUÉ HAY EN MI ESTADO”}

- Se envía enlace de Google Meet a los equipos por medio de los grupos de contacto.

- Se presenta el tema "El estado que represento" donde se ve a fondo todo lo que conforma su estado y por qué lo hace particular; en este apartado, el docente o el experto en el tema se puede enfocar en los temas que considere más importantes (ubicación geográfica, gastronomía, flora y fauna, arquitectura, personajes ilustres, deportes, folclore, música, etc.).

\section{$\bullet$} de su estado en un papel rotafolio.

- El equipo deberá ponerse de acuerdo y elegir qué van a representar de su estado.

- Cada miembro del equipo deberá presentar una categoría, mediante recortes, dibujos, imágenes digitales, etc.

- Ejemplo: Baja California, Categoría flora y fauna; se delinea el Estado y se rellenan los espacios con recortes de cimarrones, vaquitas marinas, cachanillas, cactus, etc.

- Cada miembro del equipo enviará su dibujo al grupo de contacto.

- El tema presentado quedará grabado y será enviado a los grupos de contacto para su posterior consulta.

- El equipo presentará su dibujo en la siguiente sesión, teniendo un total de 10 minutos por equipo.

- El criterio de evaluación será igual que el reto 1, será evaluada su creatividad al momento de presentar su dibujo en la sesión 4.

\begin{tabular}{l}
\multicolumn{1}{c}{ SESIÓN 4.} \\
\multicolumn{1}{c}{ EXPOSICIÓN DE MI ESTADO } \\
\hline - Se envía enlace de Google Meet a los \\
equipos por medio de los grupos de \\
contacto.
\end{tabular}

- Cada equipo tendrá 10 minutos para presentar su estado, mencionando su ubicación y capital.

- Los equipos podrán utilizar herramientas digitales para presentar su trabajo.

- El contenido de esta sesión será grabado y enviado a los grupos de contacto para consulta, ya que será necesario para cumplir con la siguiente actividad.

\section{RETO 4. "UNA CANCIÓN" (SOLO A CAPITANES)}

- El capitán del equipo elegirá una canción representativa de su estado autorizada previamente por el docente.

- Por medio de figuras geométricas el líder del equipo tendrá que representar 15 segundos de la canción, para esto el docente le enviará un ejemplo de la actividad.

- Con esta actividad obtendrán puntos extras, el líder que lo cumpla tendrá 100 puntos para su equipo.

- El docente publicará los mejores videos en el grupo de Facebook para su divulgación. 
- Se envía enlace de Google Meet a los equipos por medio de los grupos de contacto.

- Con base en lo abordado en la sesión 4, el docente creará una lista de preguntas que realizará a los equipos contrarios.

- El docente elegirá un miembro del equipo y le hará una pregunta de otro estado, pudiendo ser de cualquier categoría.

- Cada respuesta correcta obtendrá 10 puntos y cada respuesta negativa restará 10 puntos.
- Al inicio del taller, concluyendo la primera sesión, el docente enviará a los grupos de contacto una serie de pasos base de su estado, al igual que una canción representativa de su Estado con un tiempo bajo para su fácil ejecución.

- Este reto debe ser cumplido por lo menos con 3 integrantes de cada equipo.

- El alumno enviará su video bailando la canción elegida con una duración mínima de 30 segundos. Deberá utilizar el vestuario creado en el reto 1.

- El docente publicará los mejores videos en Facebook para su divulgación.

- Los equipos que se destaquen por la ejecución obtendrán los puntos como se describe en el reto 1.

\section{SESIÓN 6. “CIERRE”}

- Se envía enlace de Google Meet a los grupos de contacto.

- Menciona la importancia y beneficios del folclore mexicano.

- Se dan los resultados de la competencia, el premio queda a criterio del docente.

- Como último requisito se les envía un formulario donde contestarán preguntas relativas a las experiencias vividas en el taller.

\section{Conclusiones}

A partir del diagnóstico educativo aplicado a los participantes de estudio, el análisis de los resultados obtenidos —que reflejan un alto desinterés por el folclore mexicano, sobre todo por desconocimiento- $-\mathrm{y}$ la falta de medios de apreciación de esta disciplina artística, se optó por realizar un taller como propuesta de plan de intervención para la enseñanza de la danza folclórica mexicana.

Debido a la alerta de salubridad por la pandemia de Covid-19, que se vive a nivel mundial, ha sido necesario adecuar este taller de enseñanza multidisciplinar, basado en un entorno virtual de aprendizaje. Se empleó la metodología del ABP, puesto que el taller se diseñó para generar aprendizaje y promoción de la danza folclórica como objetivo principal, 
al mismo tiempo crear interés por la práctica de esta disciplina, al implementar un enfoque multidisciplinario en las acciones a desarrollar que orientan así la formación integral, donde además se prevé se desarrollen otras habilidades como trabajo en equipo y liderazgo (Pérez, 2005).

La danza folclórica es un elemento determinante de la cultura popular de México, por ello, al seguir fomentando e impulsando su instrucción en educación básica, se contribuye a la preservación y promoción de sus bailes y de todo lo que engloban, como vestuarios, escenarios, música, entre otros, para desarrollar la identidad nacional que debe prevalecer en los jóvenes de nuestro país. 
Capítulo 5

\section{Referencias}

Acosta, M. (2009). La educación a Distancia en República Dominicana. Revista de Educación superior, 10(1-2), 7-31. https://www.uapa. edu.do/docs/revista/Educacion\% 20Superior\% 202011.pdf

Ballestero, M. T. (2018). La Danza Folclórica de la sierra como estrategia de aprendizaje para favorecer la expresión corporal en niños y niñas de 4 años de edad. http://www.dspace.cordillera.edu.ec:8080/ xmlui/handle/123456789/4092

Barrera, R. (1997). El folclore en la educación ( $2^{\mathrm{a}}$ ed.). Ediciones Colihue.

Cobo, G., \& Valdivia, S. M. (2017). Aprendizaje basado en proyectos. Pontificia Universidad Católica del Perú. http://repositorio.pucp. edu.pe/index/handle/123456789/170374

Constitución Política de los Estados Unidos Mexicanos. (1917). Cámara de Diputados del H. Congreso de la Unión. Diario Oficial de la Federación, DOF 05-02-1917. http://www.diputados.gob.mx/ LeyesBiblio/pdf_mov/Constitucion_Politica.pdf

Estrada, J. M.(2017). La danza folclórica como propuesta para el desarrollo de recursos didácticos en función de mejorar la enseñanza de la educación artística (Tesis de licenciatura). Escuela Nacional de Danza “Nellie y Gloria Campobello”, Ciudad de México. http:// inbadigital.bellasartes.gob.mx:8080/jspui/handle/11271/1382

Ferreira, M. (2009). Un enfoque pedagógico de la danza. Educación física Chile, (268), 9-21. https://dialnet.unirioja.es/servlet/ articulo?codigo $=3237201$

Galla, S. (2018). Contribución de las danzas folklóricas al fortalecimiento en el respeto de normas de convivencia en niños de 4 años en un centro educativo particular de Pueblo Libre (Tesis de licenciatura). Pontificia Universidad del Perú, San Miguel, Perú. https://core. ac.uk/download/pdf/196532701.pdf 
García, R., \& Stalin, A. (2005). Enseñanza y aprendizaje en la educación artística. El Artista, (2),80-97. https://www.redalyc.org/ pdf/874/87400207.pdf

Hernández, M. (2015). El diagnóstico educativo, una importante herramienta para elevar la calidad de la educación en manos de los docentes. Atenas, 3(31), 63-74. https://www.redalyc.org/ pdf/4780/478047207007.pdf

Hernández-Sampieri, R., Fernández, C., \& Baptista, P. (2014). Metodología de la investigación. McGraw-Hill.

Maldonado, M. (2008). Aprendizaje Basado en Proyectos Colaborativos. Una experiencia en Educación Superior. Laurus, 14(28), 158-180. https://www.redalyc.org/articulo.oa?id=761/76111716009

Martínez, M. C. (2007). Bailar y enseñar danza folklórica: el maestro y el nacionalismo en México. https://www.redalyc.org/articulo. oa?id=76111716009

Martínez, W., Esquivel, I., \& Martínez, J. (2014). Aula invertida o modelo invertido de aprendizaje: origen, sustento e implicaciones. En I. Esquivel (Coord.), Los Modelos Tecno-Educativos, revolucionando el aprendizaje del siglo XXI (pp. 143-160). Universidad Veracruzana.

Organización de las Naciones Unidas para la Educación, la Ciencia y la Cultura. (2006). Hoja de ruta para la educación artística. Conferencia mundial sobre la educación artística. Construir capacidades creativas para el siglo XXI. Lisboa. http://www.unesco.org/new/ fileadmin/MULTIMEDIA/HQ/CLT/CLT/pdf/Arts_Edu_RoadMap_ es.pdf

Pérez, R. (2005). Sociedades multiculturales, interculturalidad y educación integral: La respuesta desde la educación personalizada. Eduga: revista galega do ensino, (45), 387-415. https://dialnet. unirioja.es/servlet/articulo?codigo $=2555367$ 
Ruiz, F. A. (2017). Diseño de proyectos STEAM a partir del Curriculum actual de Educación Primaria utilizando Aprendizaje Basado en Problemas. Aprendizaje Cooperativo, Flipped Classroom y Robótica Educativa. Universidad CEU Cardenal Herrera. http://opendata. dspace.ceu.es/handle/10637/8739

Sánchez, J. (2013). Qué dicen los estudios sobre el Aprendizaje Basado en Proyectos. Actualidad pedagógica. http://www.estuaria.es/ wp-content/uploads/2016/04/estudios_aprendizaje_basado_en_ proyectos1.pdf

Secretaría de Educación Pública. (2017). Aprendizajes Clave para la Educación Integral. Artes. Dirección General de Desarrollo Curricular. Subsecretaría de Educación Básica. SEP. México. https:// www.planyprogramasdestudio.sep.gob.mx/descargables/ARTES. pdf

Secretaría de Educación Pública. (2018). Manual del Proyecto "Bailo y juego". http://creson.edu.mx/modeloeducativo/Clubes $\% 20$ Propuestos/bailo\% 20y\% 20juego.pdf

Tamés, E. R. (2004). La enseñanza del arte en la educación básica en México (Tesis doctoral). Instituto Tecnológico y de Estudios Superiores de Monterrey, México. https://repositorio. tec.mx/bitstream/handle/11285/571992/Docs Tec_1666. pdf? sequence $=1 \&$ is Allowed $=\mathrm{y}$

Trejo, R. H. (2013). Uso de los entornos virtuales de aprendizaje en la educación a distancia. XVI Congreso Internacional EDUTEC 2013, San José, Costa Rica. https://www.uned.ac.cr/academica/edutec/ memoria/ponencias/hiraldo_162.pdf 


\section{Capítulo 6}

\section{Aprendizaje cooperativo con el apoyo del teléfono inteligente durante clases a distancia por COVID-19}

Gabriela Álvarez Plancarte, Clotilde Lomeli Agruel

y Claudia Araceli Figueroa Rochín

La educación a distancia se caracteriza por la separación del maestro y el aprendiz, así como de los aprendices entre sí (Keegan, 1996). En ella se reemplaza la comunicación presencial por un modo de comunicación mediado por la tecnología. A partir de la contingencia sanitaria causada por la CoviD-19, se adoptó este tipo de instrucción por el sistema educativo en todo el mundo.

El aprendizaje formal se vio radicalmente afectado debido a que todas las instituciones educativas se vieron obligadas a utilizar la educación a distancia prácticamente de la noche a la mañana. En el caso de México, las clases a distancia se iniciaron con una ampliación de las vacaciones de Semana Santa del 10 al 17 de abril (Secretaría de Educación Pública [SEP], 2020) y se fueron extendiendo de forma indefinida hasta terminar el primer periodo de clases. Para el segundo semestre del 2020, sin tener un panorama favorable para las clases presenciales, las instituciones educativas iniciaron el segundo ciclo escolar del año por medio de clases a distancia y continuaron de esta forma hasta finalizar el año escolar. 
El aprendizaje móvil es un tema que ha cobrado relevancia en los últimos diez años, impulsado por los avances tecnológicos en los dispositivos móviles que han incrementado su accesibilidad a la mayor parte de la población, así como los avances de cobertura de internet inalámbrico a nivel mundial (Lugo et al., 2016). De acuerdo con West y Vosloo (2013), el aprendizaje móvil “comporta la utilización de tecnología móvil, sola o en combinación con cualquier otro tipo de tecnología de la información y las comunicaciones (TIC), a fin de facilitar el aprendizaje en cualquier momento y lugar" (p.6).

La llamada generación Z, actualmente en proceso de entrar o salir de la educación superior, tiene como característica primordial que es la primera generación nacida en un ambiente cien por ciento digital. La forma como interactúan con los dispositivos móviles es distinta, muchos de ellos sienten que el teléfono inteligente forma parte de sí mismos y no conciben una vida sin uno (The Center for Generational Kinetics, 2018).

Anterior a la pandemia, el uso del teléfono inteligente durante las clases era visto por muchos docentes como una distracción (Anshari et al., 2017; Iqbal \& Bhatti, 2020; Kumar \& Radcliffe, 2019; Pinos et al., 2018) o bien, existía resistencia para su uso en clase (Berger, 2017) y en muchas instituciones su uso no era permitido. En la situación actual de contingencia, este dispositivo ha sido una herramienta invaluable para poder apoyar las clases, como medio de comunicación (entre docentes, entre alumnos y entre alumno-docente), para acceder información (correo electrónico, búsquedas en internet) y también para participar en múltiples actividades educativas tales como asistir a videoconferencias, acceder a la plataforma educativa utilizada por el centro educativo o participar en actividades grupales en línea. Estas actividades grupales, apoyadas por el método instruccional de aprendizaje cooperativo, pueden ayudar a que los estudiantes construyan sus propios entendimientos y logren aprendizajes significativos (Sharan, 2015). 
Capítulo 6

\section{Estudios de usos del teléfono inteligente en la educación}

Algunas investigaciones de usos educativos con los teléfonos inteligentes incluyen: tomar notas durante las clases (Van Wyk \& Van Ryneveld, 2018); intercambio de información académica, coordinación de trabajos grupales y consulta de servicios universitarios (Organista-Sandoval et al., 2013; Vázquez-Cano \& Sevillano, 2015); aprendizaje de matemáticas por medio de cuestionarios interactivos para evaluación formativa (Masero, 2019); uso como herramienta de enseñanza-aprendizaje en clases de historia (Fragoso et al., 2020); organización de las sesiones educativas, resolución de dudas, envío de información, discusiones y presencia social (Raiman et al., 2017); clasificación de los estudiantes con respecto al perfil de conocimiento y uso académico del teléfono inteligente (Cruz \& Barragán, 2017; Salcines-Talledo et al., 2020), así como desarrollo de habilidades cognitivas (Ramos et al., 2010), entre otros.

El aprendizaje cooperativo es un método de enseñanza comprobado por cientos de estudios como un medio que incrementa los esfuerzos de estudiantes para el logro de objetivos, impulsa las relaciones positivas entre compañeros y entre estudiantes con el docente, y mejora el bienestar y la salud psicológica (Johnson et al., 2014). Otros estudios recientes han encontrado que este método de enseñanza permite a los estudiantes un mejor entendimiento de los conceptos y mejores logros de aprendizaje, por lo tanto, es considerado como un facilitador del aprendizaje (Eymur \& Geban, 2017; Sangadji, 2016; Silva et al., 2020), entre otros. La contingencia sanitaria justifica aprovechar este método instruccional, para promover un aprendizaje significativo en los estudiantes. Este se entiende como aquel que sucede cuando las ideas expresadas de forma simbólica se relacionan de forma no arbitraria y substantiva (no textual) a lo que el aprendiz ya sabe (Ausubel et al., 1978).

Este trabajo explora formas en que el teléfono inteligente puede apoyar el aprendizaje significativo, utilizando diversas estrategias 
cooperativas durante clases a distancia con estudiantes de educación superior del ciclo escolar agosto-diciembre del 2020.

\section{Descripción del escenario}

El estudio se realizó con dos grupos, 37 estudiantes en total, de primer semestre de la licenciatura de Odontología, en la asignatura de Bioquímica. El rango de edad fue de 17 a 26 años, integrado por 13 hombres y 23 mujeres. El centro educativo es una universidad privada en Mexicali, Baja California, México, donde la carrera de Odontología es de reciente formación. En el ciclo agosto-diciembre 2020 tenía alumnos inscritos hasta el sexto semestre, de un total de nueve semestres contemplados para terminar la carrera.

La asignatura de Bioquímica tiene la particularidad de ser una materia básica, primordialmente teórica, en la que se imparten muchos conceptos abstractos. De acuerdo con las experiencias previas al impartir la clase, es importante buscar ejemplos cotidianos para relacionar los diferentes temas, ya que de otro modo los estudiantes presentan dificultad para contextualizar o encontrar aplicaciones prácticas de los temas estudiados. Una forma de lograr esto, es trabajando en equipos de manera cooperativa, de manera que los estudiantes discutan acerca de los temas o términos difíciles de entender y encuentren las respuestas por sí mismos.

\section{Objetivo}

El objetivo de la investigación fue conocer las formas en las que los teléfonos inteligentes apoyan las actividades de aprendizaje cooperativas en clases a distancia para promover aprendizajes significativos en los estudiantes. Para cumplir con el objetivo, se formularon las siguientes preguntas de investigación: 
- ¿Cuáles son las formas como los alumnos trabajan en equipo de manera cotidiana?

- ¿De qué manera se apoyan los estudiantes con el teléfono inteligente en sus actividades académicas?

- De acuerdo con su retroalimentación, ¿Qué actividades de aprendizaje cooperativo tienen un mayor impacto en los aprendizajes significativos de los alumnos?

- ¿Cuál es la opinión de los estudiantes con respecto a su experiencia con las actividades cooperativas realizadas?

\section{Metodología}

El estudio fue de tipo cualitativo exploratorio, utilizando un diseño de investigación-acción participativa crítica, tal como lo describen McTaggart et al. (2017), bajo una perspectiva subjetiva individual. La metodología utilizada está basada en el estudio realizado por Raiman et al. (2017) con estudiantes de medicina, adaptada a la instrucción a distancia. Los instrumentos de recolección de datos utilizados fueron: cuestionarios semiestructurados aplicados a lo largo del ciclo escolar, interacciones realizadas por medio de la aplicación de WhatsApp (grupal e individual), videoconferencias grabadas de las clases y entrevistas individuales con estudiantes (grabadas y transcritas). No todos los estudiantes participaron en todas las actividades de recolección de datos y las muestras se realizaron por conveniencia de acuerdo con la disponibilidad de los estudiantes. Los cuestionarios se agruparon por tipos de respuestas, para conocer lo que la mayoría opinaba. Para el caso de las entrevistas y las preguntas abiertas, se realizó un análisis de contenido a partir de categorías de análisis y códigos, además de cuantificación de respuestas utilizando porcentajes. El programa utilizado para los cálculos fue Microsoft Excel. Las unidades de análisis y códigos utilizados se presentan en la tabla 1. 


\section{Tabla 1}

\section{Unidades y categorías de análisis}

\begin{tabular}{|c|c|c|c|}
\hline & $\begin{array}{l}\text { Unidad de análisis 1: } \\
\text { aprendizaje cooperativo }\end{array}$ & & $\begin{array}{l}\text { Unidad de análisis 2: } \\
\text { aprendizaje móvil }\end{array}$ \\
\hline Código 1 & Relaciones intergrupales positivas & Código 1 & $\begin{array}{l}\text { Uso del teléfono inteligente para } \\
\text { comunicación }\end{array}$ \\
\hline Código 2 & Responsabilidad individual & & \\
\hline Código 3 & Interacción promotora & Código 2 & $\begin{array}{l}\text { Uso del teléfono inteligente para } \\
\text { investigación }\end{array}$ \\
\hline Código 4 & $\begin{array}{l}\text { Uso apropiado de habilidades } \\
\text { sociales }\end{array}$ & & \\
\hline Código 5 & $\begin{array}{l}\text { Procesamiento en grupo/evalua- } \\
\text { ción recíproca }\end{array}$ & Código 3 & $\begin{array}{l}\text { Uso del teléfono inteligente para } \\
\text { actividades de aprendizaje }\end{array}$ \\
\hline Código 6 & Retos para trabajar en equipos & & \\
\hline
\end{tabular}

\section{Resultados}

\section{Unidad de análisis - Aprendizaje cooperativo}

Para promover un aprendizaje significativo por medio del aprendizaje cooperativo, se utilizaron los cinco principios descritos por Johnson et al. (2014):

1. Relaciones intergrupales positivas: el éxito de uno no es posible sin el éxito del grupo.

2. Responsabilidad individual: realizar evaluaciones individuales y grupales.

3. Interacción promotora: ayuda, asistencia, incentiva y soporte entre estudiantes.

4. Uso apropiado de habilidades sociales: liderazgo, toma de decisiones, confianza, comunicación y resolución de conflictos.

5. Procesamiento en grupo / Evaluación recíproca.

Además, se incluyó el código dentro de esta unidad de análisis:

6. Retos para trabajar en equipo (debido a las clases a distancia). 
Durante el semestre se realizaron actividades en clase y tareas en equipo para utilizar esta estrategia instruccional. Los cinco principios y algunos ejemplos de las retroalimentaciones recibidas por los estudiantes se detallan a continuación.

Relaciones intergrupales positivas

Al iniciar el semestre se realizó un foro para presentar a los miembros del grupo. Cada estudiante debía aportar una breve introducción de sí mismo, compartiendo la información que quisieran (edad, lugar de nacimiento, deportes o actividades favoritas, etc.) y se les impulsó a comentar acerca de lo que sus compañeros compartían. Se establecieron reglas de interacción tales como respeto a las publicaciones de otros y prohibición de lenguaje altisonante o burlas. Esta actividad ayudó a mejorar las relaciones intergrupales. Además, se realizaron actividades en equipos, rotando a los integrantes al azar, incrementando la interacción entre los estudiantes. Al final del primer parcial se realizaron 22 entrevistas individuales y las retroalimentaciones se muestran en la tabla 2.

\section{Tabla 2}

\section{Retroalimentación de los alumnos con respecto a relaciones intergrupales positivas}

\begin{tabular}{cl}
\hline $\begin{array}{c}\text { Código } \\
\text { del alumno }\end{array}$ & \multicolumn{1}{c}{ Retroalimentación recibida } \\
\hline Sujeto 1 & $\begin{array}{l}\text { lo de los trabajos en equipos pues se me hace muy bien porque (...) he conocido } \\
\text { más a mis compañeros }\end{array}$ \\
\hline & $\begin{array}{l}\text { me gustó mucho que nos hiciera como trabajar en equipo, para poder conversar } \\
\text { con los compañeros, para tener como acercamiento con ellos, que no tenemos } \\
\text { porque no estamos viéndonos en persona... entonces, creo que eso sí me gustó } \\
\text { mucho... }\end{array}$ \\
\hline Sujeto 2 & $\begin{array}{l}\text { Pues lo del equipo está bien, pues como usted dice, no nos conocemos, y así nos } \\
\text { vamos conociendo mejor, interactuamos, platicamos... }\end{array}$ \\
\hline
\end{tabular}

Nota. Los comentarios fueron escritos por los estudiantes, se transcribieron tal como se realizaron. 
Capítulo 6

\section{Responsabilidad individual}

Se instituyó un método de calificación individual y grupal, de manera que cada estudiante obtenía su calificación del promedio de una calificación individual y otra grupal. Las calificaciones individuales y grupales se reportaron a todo el equipo, de forma que todos estuvieran enterados de la calidad de sus contribuciones al trabajo grupal. En esta categoría, los estudiantes retroalimentaron en el cuestionario de final del semestre, donde se preguntó lo que se considera más importante para que un trabajo en equipo sea exitoso, es decir, que todos tengan el máximo de calificación y aprendan. Ejemplos de las respuestas obtenidas se enlistan en la tabla 3.

\section{Tabla 3}

Retroalimentación de los alumnos con respecto a responsabilidad individual

\begin{tabular}{cl}
\hline $\begin{array}{c}\text { Código } \\
\text { del alumno }\end{array}$ & \multicolumn{1}{c}{ Retroalimentación recibida } \\
\hline Sujeto 4 & $\begin{array}{l}\text { lo más importante es que todo el equipo sea atento y responsable de lo que se le } \\
\text { pide }\end{array}$ \\
\hline Sujeto 5 & $\begin{array}{l}\text { es muy importante que todos nos hagamos responsables y estar al pendiente lo } \\
\text { más que podamos }\end{array}$ \\
\hline Sujeto 6 & Que todas las personas trabajen y que cada quien haga su parte correctamente \\
\hline
\end{tabular}

Nota. Los comentarios fueron escritos por los estudiantes, se transcribieron tal como se realizaron.

\section{Interacción promotora}

En este apartado no todos los equipos lograron este tipo de interacción, aunque hubo algunos ejemplos exitosos, los cuales se transcriben en la tabla 4. 
Capítulo 6

\section{Tabla 4}

\section{Retroalimentación de los alumnos con respecto a responsabilidad individual}

\begin{tabular}{cl}
\hline $\begin{array}{c}\text { Código } \\
\text { del alumno }\end{array}$ & \multicolumn{1}{c}{ Retroalimentación recibida } \\
\hline Sujeto 3 & $\begin{array}{l}\text { hacemos grupos y nos preguntamos las cosas, hacemos lo que nos toca a cada quien } \\
\text { y así...o sea no batallamos en que alguien no haga las cosas y así, pero siempre } \\
\text { aprendemos. Si no sabemos algo nos preguntamos y nos ayudamos, así. }\end{array}$ \\
\hline \multirow{3}{*}{ Sujeto 7} & $\begin{array}{l}\text { entonces todo lo hicimos como que... a lo mejor si yo lo hubiera hecho nada más me } \\
\text { hubiera quedado con la sola opinión de mis apuntes que yo sé que igual y es lo mis- } \\
\text { momplo ya solo fuimos agarrando un poquito de aquí, un poquito de allá y si nos } \\
\text { complamos. No le flojeó ni él ni JR, era de que ah, miren puse esta respuesta, } \\
\text { vean como esta, de esta ayudo poquito, ah ok deja la vamos a checar... }\end{array}$ \\
\hline & $\begin{array}{l}\text { A mí el trabajo en equipo sobre la guía se me hizo bien porque, ya sea por el número } \\
\text { de personas que tenía en el equipo, yo me integré con [GD] y ambas pudimos com- } \\
\text { partir como respuestas. Si una ya no se acordaba muy bien de otra pues ya nos dá- } \\
\text { bamos una explicación, o ya buscábamos información en las diapositivas, si no nos } \\
\text { quedaba muy claro ya nos explicábamos, mirábamos un video o algo por el estilo... }\end{array}$ \\
\hline
\end{tabular}

Nota. Los comentarios fueron escritos por los estudiantes, se transcribieron tal como se realizaron.

Uso apropiado de habilidades sociales

Para este código, un ejemplo mencionado por uno de los alumnos durante las entrevistas fue:

Pues las actividades en equipo están bien, porque bueno a mí, con los que me ha tocado nuestros compañeros siempre nos estamos apoyando. (Sujeto 3)

En el cuestionario de final de semestre, en la pregunta acerca de los aspectos de importancia para que un trabajo sea exitoso, es decir, que tenga el máximo de calificación y aprendan, algunos estudiantes profundizaron un poco más sobre el aspecto de las habilidades sociales, sus contribuciones se mencionan en la tabla 5. 
Capítulo 6

\section{Tabla 5}

Retroalimentación de los alumnos respecto al uso apropiado de habilidades sociales

\begin{tabular}{cl}
\hline $\begin{array}{c}\text { Código } \\
\text { del alumno }\end{array}$ & \multicolumn{1}{c}{ Retroalimentación recibida } \\
\hline Sujeto 2 & $\begin{array}{l}\text { Que nos apoyemos cuando lo necesitemos para poder complementar la información } \\
\text { de la investigación. }\end{array}$ \\
\hline Sujeto 9 & $\begin{array}{l}\text { El apoyo entre todos. Talvez yo no sepa algo pero un compañero de equipo sí y me } \\
\text { ayuda en eso, y talvez mi compañero no sepa de algo pero yo sí y lo apoyo. Y asi si } \\
\text { nos apoyamos entre todos y hay comunicación, el trabajo será exitoso. }\end{array}$ \\
\hline Sujeto 8 & $\begin{array}{l}\text { que seamos empáticos, que si alguien necesita ayuda se le dé, que haya comunica- } \\
\text { ción. }\end{array}$ \\
\hline
\end{tabular}

Nota. Los comentarios fueron escritos por los estudiantes, se transcribieron tal como se realizaron.

Procesamiento en grupo / evaluación recíproca

Este aspecto fue considerado en la pregunta acerca de los elementos importantes para un trabajo en equipo exitoso. Se muestran ejemplos en la tabla 6.

\section{Tabla 6}

\section{Retroalimentación de los alumnos con respecto a procesamiento en grupo / evaluación recíproca}

\begin{tabular}{cc}
\hline $\begin{array}{c}\text { Código } \\
\text { del alumno }\end{array}$ & Retroalimentación recibida \\
\hline Sujeto 10 & $\begin{array}{l}\text { dar nuestros puntos de vista ya que si yo puedo ayudar a mejorar lo que mi compañero } \\
\text { hizo es fundamental para entregar un trabajo de calidad. Críticas constructivas son las } \\
\text { que te hacen mejorar en todos los aspectos }\end{array}$ \\
\hline Sujeto 11 & el respeto a las ideas de los demás y querer aportar algo al equipo y ayudar a los demás \\
\hline
\end{tabular}

Nota. Los comentarios fueron escritos por los estudiantes, se transcribieron tal como se realizaron. 
Capítulo 6

Retos para trabajar en equipos a distancia

Dentro de esta categoría de análisis, se presentaron algunos conflictos internos que no fueron detectados sino hasta el final, debido a que los equipos no los externaron con el docente. En algunos casos, impactó en la calidad de los trabajos o simplemente alguno de los integrantes tomó control para poder entregar el trabajo completo. Esto se dio en mayor medida al principio del semestre, ya que conforme progresaron las clases se fueron integrando los equipos con las personas que se complementaron mejor para trabajar juntas. Algunos de los problemas externados por los alumnos en las entrevistas individuales se muestran en la tabla 7.

\section{Tabla 7}

\section{Retroalimentación de alumnos con respecto a retos de trabajos en equipo (clases a distancia)}

\begin{tabular}{cl}
\hline $\begin{array}{c}\text { Código } \\
\text { del alumno }\end{array}$ & \multicolumn{1}{c}{ Retroalimentación recibida } \\
\hline Sujeto 12 & $\begin{array}{l}\text { las primeras veces cuando usted nos hacia los equipos porque no nos conocíamos... } \\
\text { he... algunos pues no trabajaban y así...y como que ¡ay! }\end{array}$ \\
\hline \multirow{2}{*}{ Sujeto 2} & $\begin{array}{l}\text { Nada más que...pues también es difícil...como explicarlo todo... pues en un mensa- } \\
\text { je, no sé, siento que es un poco complicado ponerse de acuerdo o que... te respon- } \\
\text { dan a tiempo, porque están haciendo otras cosas, no sé }\end{array}$ \\
\hline \multirow{2}{*}{ Sujeto 4} & $\begin{array}{l}\text { Cuando me toca con algunos que conozco pues si hablo con ellos, pero con los de- } \\
\text { más casi no hablo pues...porque no los conozco y como que pues... es bien diferen- } \\
\text { te así por computadora pues }\end{array}$ \\
\hline
\end{tabular}

Nota. Los comentarios fueron escritos por los estudiantes, se transcribieron tal como se realizaron.

\section{Unidad de Análisis: Aprendizaje móvil}

Dentro de las interacciones realizadas por medio del teléfono inteligente, se analizó la forma como los estudiantes utilizan este dispositivo de manera cotidiana y si ellos consideran que es un apoyo para sus actividades académicas. Los códigos estudiados con respecto al aprendizaje 
móvil fueron: interacciones para comunicación, investigación y actividades de aprendizaje.

\section{Uso del teléfono inteligente para comunicación}

En relación con este código, en las entrevistas individuales a principios del semestre se confirmó que los salones tenían un grupo de WhatsApp exclusivo para los estudiantes, el cual utilizaban para comunicarse entre sí con respecto a las clases. En uno de los cuestionarios, se les preguntó de qué forma les ayudaba el teléfono inteligente como apoyo para sus clases. En respuesta, uno de los alumnos comentó lo siguiente:

para comunicarme con mi profesora o mis compañeros ocupamos usar el celular ya que es la vía más rápida ya sea para ponernos de acuerdo en trabajos en equipo o para preguntar sobre nuestras dudas. (Sujeto 10)

\section{Uso del teléfono inteligente para investigación y aprendizaje}

Dentro de los cuestionarios, se preguntó a los estudiantes si consideraban que el teléfono inteligente los había ayudado en la clase. De las respuestas obtenidas para ambos grupos tres cuartas partes de los estudiantes lo consideraban de mucha ayuda, mientras un $22 \%$ respondió que no le ayuda ni afecta para sus clases y solamente el 3\% restante contestó que no consideraba que lo ayudaba en sus clases. La respuesta principal que dieron los estudiantes de las formas en que les ayudaba fue, para buscar información rápidamente o aclarar conceptos que no entienden durante la clase (64\% del total de respuestas). Las actividades de aprendizaje realizadas con este dispositivo fueron principalmente de forma individual entre docente y alumnos, para resolver dudas acerca de tareas o aclarar algún concepto visto en clase. 
Capítulo 6

\section{Conclusiones}

El estudio encontró que el método instruccional de aprendizaje cooperativo promueve las relaciones interpersonales positivas en el grupo, pero requiere seguimiento del docente con respecto a la responsabilidad individual dentro de cada equipo y asegurar la participación de todos. Esto por medio de una comunicación estrecha con los equipos y realizando revisiones periódicas del estado de los trabajos, especialmente en aquellos que requieren mayor tiempo o son más complejos. Este proceso es más difícil con las clases a distancia, porque el tiempo para interactuar con los alumnos durante las clases es limitado. En las sesiones síncronas se promovió con los alumnos el contacto con el docente fuera del horario de clases por medio de la aplicación de WhatsApp, lo que se aprovechó como un apoyo adicional, sin embargo, no todos los estudiantes tuvieron la confianza para acercarse por este medio.

Las actividades de aprendizaje cooperativo utilizadas en clase fueron evaluadas por los estudiantes de forma positiva, aunque cada estudiante tuvo preferencia por distintas estrategias didácticas. El uso del teléfono inteligente sirvió principalmente como medio de comunicación continua, para envío de información y resolución de dudas.

Existieron muchas limitantes en este estudio, entre las que se encuentran: duración del estudio, número de estudiantes, falta de comparativos de experiencias con otras asignaturas u otros docentes, falta de experiencia para adaptar la asignatura en un modo a distancia durante todo el ciclo escolar, así como la aplicación de estrategias didácticas cooperativas en esta modalidad.

La contingencia sanitaria global fue una situación inusitada que obligó a los docentes a utilizar herramientas tecnológicas tales como el teléfono inteligente de formas innovadoras. Seguir investigando y aprovechando el potencial educativo que pueden promover estos dispositivos será de gran utilidad en el futuro. 
Capítulo 6

\section{Referencias}

Anshari, M., Almunawar, M. N., Shahrill, M., Wicaksono, D. K., \& Huda, M. (2017). Smartphones usage in the classrooms: Learning aid or interference? Educ Inf Technol, 22, 3063-3079. https://doi. org/10.1007/s10639-017-9572-7

Ausubel, D. P., Novak, J. D., \& Hanesian, H. (1978). Educational Psychology: A cognitive view (2a ed.). Holt, Rinehart and Winston.

Berger, P. (2017). Beyond plain acceptance or sheer resistance: A typology of university instructors' attitudes to students' media use in class. Teaching and Teacher Education, 67, 410-417. https://doi. org/10.1016/j.tate.2017.07.009

Cruz, A., \& Barragán, A. D. (2017). Percepción del uso educativo del teléfono inteligente en estudiantes de la Universidad de la Sierra Sur. Temas de Ciencia y Tecnología, 21(61), 29-40.

Eymur, G., \& Geban, Ö. (2016). The Collaboration of Cooperative Learning and Conceptual Change: Enhancing the Students' Understanding of Chemical Bonding Concepts. International Journal of Science and Mathematics Education, 15, 853-871. https://doi.org/10.1007/ s10763-016-9716-z

Fragoso, J., Trujillo, J. A., Molina, A. M., Olano, M., Caminero, V., \& Sarduy, S. (2020). Experiencia sobre el uso del teléfono móvil como herramienta de enseñanza y aprendizaje en clases de Historia: percepción de los estudiantes. MediSur, 18(4), 605-613. http:// www.redalyc.org/articulo.oa?id=180064571010

Iqbal, S., \& Bhatti, Z. A. (2020). A qualitative exploration of teachers' perspective on smartphones usage in higher education in developing countries. International Journal of Educational Technology in Higher Education, 17, 1-16. https://doi.org/10.1186/s41239-020-00203-4 
Johnson, D. W., Johnson, R. T., \& Smith, K.A. (2014). Cooperative learning: Improving university instruction by basing practice on validated theory. Journal on Excellence in College Teaching, 25(3-4), 85-118.

Keegan, D. (1996). Foundations of Distance Education (3a ed.). Routledge. Kumar, D. K., \& Radcliffe, P. (2019). Teaching Surrounded by Smart Phones. Springer. https://doi.org/10.1007/978-981-15-1401-2

Lugo, M.T., Ruiz, V., Brito, A., \&Brawerman,J.(2016). Revisión comparativa de iniciativas nacionales de aprendizaje móvil en América Latina: Los casos de Colombia, Costa Rica, Perú y Uruguay. UNESCO.

Masero, I. C. (2019). Móviles y aprendizaje en la educación superior. 3C TIC. Cuadernos de desarrollo aplicados a las TIC, 8(4), 13-25. https://doi.org/10.17993/3ctic.2019.84.13-25

McTaggart, R., Nixon, R., \& Kemmis, S. (2017). Critical Participatory Action Research. En L. L. Rowell, C. D. Bruce, J. M. Shosh, \& M. M. Riel (Eds.), The Palgrave International Handbook of Action Research (pp. 21-36). Palgrave MacMillan. https://doi.org/10.1057/978-1137-40523-4_2

Organista-Sandoval, J., Serrano-Santoyo, A., McAnally-Salas, L., \& Lavigne, G. (2013). Apropiación y usos educativos del celular por estudiantes y docentes universitarios. Revista Electrónica de Investigación Educativa, 15(3), 138-156. http://redie.uabc.mx/ vol15no3/contenido-organistaetal.html

Pinos, N. Y., Hurtado, S. N., \& Rebolledo, D. M. (2018). Uso del teléfono celular como distractor del proceso enseñanza-aprendizaje. Enfermería Investiga, Investigación, Vinculación, Docencia y Gestión, 3(4), 166-171. https://doi.org/10.29033/ei.v3n4.2018.02

Raiman, L., Antbring, R., \& Mahmood, A. (2017). WhatsApp messenger as a tool to supplement medical education for medical students on clinical attachment. BMC Medical Education, 17(7), 1-9. https:// doi.org/10.1186/s12909-017-0855-x 
Ramos, A. I., Herrera, J. A., \& Ramírez, M. S. (2010). Desarrollo de habilidades cognitivas con aprendizaje móvil: Un estudio de casos. Comunicar, 17(34), 201209. https://doi.org/10.3916/C34-2010-0320

Salcines-Talledo, I., González-Fernández, N., \& Briones, E. (2020). The Smartphone as a Pedagogic Tool. Student Profiles as related to its Use and Knowledge. Journal of New Approaches in Educational Research, 9(1), 91-109. https://doi.org/10.7821/naer.2020.1.454

Sangadji, S. (2016). Implementation of cooperative learning with group investigation model to improve learning Achievement of vocational school students in Indonesia. International Journal of Learning $\mathcal{E}$ Development, 6(1), 91-103.

Secretaría de Educación Pública. (2020). Comunicado conjunto No. 3: Presentan Salud y SEP medidas de prevención para el sector educativo nacional por COVID-19. https://www.gob.mx/sep/ es/articulos/comunicado-conjunto-no-3-presentan-salud-y-sepmedidas-de-prevencion-para-el-sector-educativo-nacional-porcovid-19?idiom=es

Sharan, Y. (2015). Meaningful Learning in the Co-operative Classroom. Education 3-13: International Journal of Primary, Elementary and Early Years Education, 43(1), 83-94. https://doi.org/10.1080/03004 279.2015.961723

Silva, M. A., Cantanhede, L. B., \& Silva, S. C. (2020). Aprendizagem cooperativa: método jigsaw, como facilitador de aprendizagem do conteúdo químico separação de misturas. Actio: Docência em Ciências, 5(1), 1-21. https://doi.org/10.3895/actio.v5n1.9323

The Center for Generational Kinetics. (2018). The State of Gen Z 2018: Unexpected insights into how Gen $Z$ is impacting everything from technology and brands to social media and the workplace. https:// genhq.com/ 
Van Wyk, M., \& Van Ryneveld, L. (2018). Affordances of mobile devices and note-taking apps to support cognitively demanding note-taking. Education and Information Technologies, 23(4), 1639-1653. https:// doi.org/10.1007/s10639-017-9684-0

Vázquez-Cano, E., \& Sevillano, M. L. (2015).El smartphone en la educación superior. Un estudio comparativo del uso educativo, social y ubicuo en universidades españolas e hispanoamericanas. Signo y Pensamiento, 34(67), 114. https://doi.org/10.11144/Javeriana. syp34-67.sese

West, M., \& Vosloo, S. (2013). Directrices de la UNESCO para las políticas de aprendizaje móvil. UNESCO. 
Qartuppi, S. de R.L. de C.V. está inscrita de forma definitiva en el Registro Nacional de Instituciones y Empresas Científicas y Tecnológicas (RENIECYT) con el número 1600052.

Qartuppi, S. de R.L. de C.V. es miembro activo

de la Cámara Nacional de la Industria Editorial Mexicana (CANIEM) con número de registro 3751.

Investigación, gestión

y procesos formativos en educación

Esta obra se terminó de producir en septiembre de 2021.

Su edición y diseño estuvieron a cargo de:

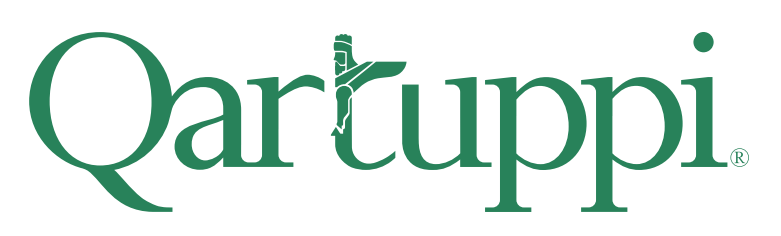

Qartuppi, S. de R.L. de C.V.

http://www.qartuppi.com 


\section{(c) (i) () ()}

Esta obra se edita bajo una licencia Creative Commons

Atribución-NoComercial-CompartirIgual 4.0 Internacional. 
El libro Investigación, gestión y procesos formativos en educación es resultado de la suma de esfuerzos de estudiantes y miembros del núcleo académico de

la Maestría en Educación de la Universidad Autónoma de Baja California

(UABC). A través de seis capítulos, presenta las experiencias de aplicación teórico metodológicas para el diseño de proyectos de intervención educativa en el ámbito de la gestión y los procesos formativos, donde convergen distintas miradas disciplinares que permiten ver la complejidad de la realidad en los contextos educativos, así como la necesidad constante de analizar, reflexionar y

- A transformar la propia práctica profesional. 